\title{
Translations and Boundaries in the Gap Between HCI Theory and Design Practice
}

\author{
RAPHAEL VELT, Breda University of Applied Sciences, Netherlands \\ STEVE BENFORD, School of Computer Science, University of Nottingham, UK \\ STUART REEVES, School of Computer Science, University of Nottingham, UK
}

\begin{abstract}
The gap between research and design practice has long been a concern for the $\mathrm{HCl}$ community. In this paper, we explore how different translations of $\mathrm{HCl}$ knowledge might bridge this gap. A literature review characterizes the gap as having two key dimensions-one between general theory and particular artefacts and a second between academic $\mathrm{HCl}$ research and professional UX design practice. We report on a fiveyear engagement between $\mathrm{HCl}$ researchers and a major media company to explore how a particular piece of $\mathrm{HCl}$ research, the trajectories conceptual framework, might be translated for and with UX practitioners. We present various translations of this framework and fit them into the gap we previously identified. This leads us to refine the idea of translations, suggesting that they may be led by researchers, by practitioners, or co-produced by both as boundary objects. We consider the benefits of each approach.
\end{abstract}

\section{CCS Concepts: XXXX}

\section{KEYWORDS}

HCI Theory; Dissemination; Impact; Translation; Translational research; Trajectories; Research-Practice Gap.

\section{ACM Reference format:}

XXXX.

\section{DOI: XXXX}

\section{INTRODUCTION}

Despite some sections of the Human-Computer Interaction research community priding itself on its impact on industrial design [53], there is a growing concern about the apparent "gap between $\mathrm{HCl}$ research aimed at influencing interaction design practice and the practitioners in question" $[26,46,45]$, leading to the formation of a special interest group on Research-Practice Interaction (RPI) [5, 6]. However, the precise nature of this gap is contested, while the ways to bridge it remain far from clear [1]. Some have argued that the gap arises from a disconnection between high level theory and "low-level" design practice, with the former not being directly applicable to $[24,48]$ or grounded in [56] the latter. Others see the gap as being between different communities of practice [26] - the academic $\mathrm{HCl}$ community and the UX practitioner community-whose stakeholders are characterized as being driven by different values, such as that of generalizing knowledge versus creating the ultimate concrete particulars of designs [39]. Yet others have characterized the gap as being a metaphor that "frames problems and guides researchers towards possible solutions" [1].

When it comes to bridging the gap, there has been much focus on how various kinds of translation can support the "trickle down" of theory into practice $[48,56]$ or of how different

Permission to make digital or hard copies of part or all of this work for personal or classroom use is granted without fee provided that copies are not made or distributed for profit or commercial advantage and that copies bear this notice and the full citation on the first page. Copyrights for third-party components of this work must be honored. For all other uses, contact the owner/author(s). 
forms of "intermediate design knowledge" such as heuristics, guidelines, patterns, strong concepts, methods, tools, and others may bridge between abstract theory and particular artefacts [35]. An alternative view is that translation is embodied in people: practitioners who may be distinct from both researchers and designers [40]. We return to these and other perspectives in subsequent discussions. What we do note, however, is a general paucity of accounts of practical attempts to bridge the gap, although there is an emerging literature focussing on some aspects of this $[27,11]$. Colusso and colleagues, for instance, have recently proposed to apply a model of Translational Sciences to the research-practice gap in $\mathrm{HCl}$, and have called for the production of studies of engagement between both sides of the gap, of which the present article is an example [12]. $\mathrm{HCl}$ thus needs more documented cases that might inform improved conceptual reflections on the gap and how $\mathrm{HCl}$ constructs it with respect to theory and practice, academia and industry.

In response to this, we report a case study: a five-year long engagement between $\mathrm{HCl}$ researchers and a UK-based major media organization to endeavour to translate a particular piece of $\mathrm{HCl}$ academic "theory" into UX research and design. This case study initially arose jointly from our interest as researchers in seeing greater impact of our work and in the company's interest in whether a particular piece of $\mathrm{HCl}$ theory-the trajectories conceptual framework [4]-could inform their thinking about how to design more joined-up multiscreen media experiences. This initial mutual interest spawned a series of engagement activities to try and put the theory to work in practice by the company's UX team; to translate it with the exigencies of practitioners' work in mind. We attempted this via various means: extended visits by researchers, presentations, documented case studies, and consultancy on live projects, new diagramming techniques and use of ideation cards. Reflecting on this experience from the perspective of academic researchers in relation to the wider $\mathrm{HCl}$ literature leads us to reexamine how gaps are constructed between $\mathrm{HCl}$ theory and UX practice (and indeed the very characterizations of those domains with "theory" and "practice" respectively). In doing this we try to answer a series of questions: What is the nature of the gap? Why might various stakeholders wish to bridge it? What kinds of translations might be useful? Why is it challenging to translate $\mathrm{HCl}$ theory into the work of industry $\mathrm{UX}$ researchers and designers?

Our reflections lead us to consider various different modes in which translation work can proceed, each with their various pros and cons. The first is perhaps most familiar, $\mathrm{HCl}$ researcher-led translations that turn on the sharing of research with UX practitioners in ways driven by a more traditional conception of "knowledge transfer". In the second mode, translations are jointly developed through partnerships between $\mathrm{HCl}$ academics and UX practitioners. In the third, they are led by UX practitioners. The "gap" thus becomes a matter of conceptualization and configuration between different stakeholders.

\section{THE APPARENT GAP BETWEEN THEORY AND PRACTICE IN HCI}

One of the ways the RPI community has suggested for bridging the research-practice gap is the development of "translations" between research and practice [5, 6]. Although our particular focus in this paper is on translations from academic research into industry practice, we recognize other possibilities and return to them later in the paper. One notable suggestion is from Norman [40], who argues that translational development could be the remit of a particular practitioner role distinct from both researchers and designers. There are also 
documented cases of designers producing their own translations [25] (a move we discuss in more detail later).

We now turn to the literature to better understand the nature of such translations and of the gap that they are attempting to bridge. We characterize this gap in terms of two distinct dimensions, one spanning different practices, such as academic $\mathrm{HCl}$ research and industry UX work, and the second spanning different levels of abstraction from general theory to particular artefacts. Part of our intended contribution is to try and disentangle any notion that academic $\mathrm{HCl}$ is equivalent to theory and industry $\mathrm{UX}$ to practice, by emphasizing that $\mathrm{HCl}$ engages with practice and UX with theory, albeit in their own ways.

\subsection{Characterizing the gap as communities of practice}

Consistent with previous literature [27], we characterize the "gap" as being between different "practices", a word describing patterns of knowing and doing things based on shared understandings [52, 44]. Given the social nature of practices, they are often structured around "communities of practice" [33] that orient toward common "stakes". So, our sense of the "gap" thus becomes that of a gap between different communities of practice which revolve around different stakes. On the research side, one example of such a group of people organized around the common practice of $\mathrm{HCl}$ academic research may be the " $\mathrm{CHI}$ community"-although there are of course several other $\mathrm{HCl}$ communities (see [46, p. 3]). On the industry side, the community of practice may be the "emergent discipline" of "User Experience" (UX) [31, 50], but which may also be cross over into other characterizations like "interaction design", "experience design", or "service design" amongst many".

This presentation of the gap is somehow symmetrical, as it depicts $\mathrm{HCl}$ research as something of the same nature as the work of UX practitioners ${ }^{2}$. Discussing academic research as a practice is at the core of science and technology studies (STS) [32], a field of study whose influence on $\mathrm{HCl}$ has included critical reflections on core concepts in the $\mathrm{HCl}$ discourse-e.g., the "user" [13] - and on the discipline's publication practices [9].

Literature on design practice $[39,56]$ that contrasts such practice with research activities helps us understand how the stakes differ on both sides of the gap. One common measure of success for research is to produce generalizable knowledge, while for design, the yardstick is the production of solutions to concrete problems. In other words [39, 18], a familiar caricature is that researchers strive for "true", "universal" and "abstract" knowledge, while designers aim at the "real" or "ultimate particular", describing the concrete forms of the output of design. Another way to look at it is to consider how the work of individuals on each side of the gap is assessed: while researchers tend to be judged primarily (although not only) on their output in terms of published papers, UX (including design) practitioners tend to be assessed on the quality and commercial success of the artefacts they design (although other factors may come into play, such as the measure to which they display so-called "thought leadership").

\footnotetext{
1 (At this point we emphasize two points: firstly that naturally as academics we represent a particular sidedness or stance with respect to our descriptions and positionings of relations between these communities; and secondly we want to dispel any implied hierarchies of knowledge between academia research and industry practice, as suggested by concepts like "transfer", and hence why we prefer the term "translation" in this article to characterize relations as like interactions between two different language communities. Note that the notion of translation is different again from "contact languages" [22].)

${ }^{2}$ For that reason, we thereafter refrain from using the word "practice" in isolation to designate professional design practice.
} 
We nuance these differences by stressing that the activities of $\mathrm{HCl}$ academic research communities and those of UX practitioner communities may not be that different. Some of the people, such as key figures like Donald Norman or Jakob Nielsen, tend to span both worlds. The definitions of the discipline of UX also show significant overlap between both communities of practice [50]. Designing artefacts is also a core part of the activities of researchers (for example as a result of HCl's growing interest in Research Through Design [60])and we must recognize that producing and disseminating abstract knowledge is not the exclusive domain of academic $\mathrm{HCl}$ but something industry user research and design professionals also do-for example, publishing frameworks like Garrett's "dimensions of user experience" [23], Young's "mental models" [62], or giving talks to professional audiences at international conferences (such as those organised by the User Experience Professionals Association (UXPA), Interaction Design Association (IxDA), or Information Architecture Institute (IAI)). These activities may be rewarded to some extent, as academic researchers may be evaluated on their "impact" (in the UK for example, research proposals routinely include a mandatory impact section and the Government's Research Excellence Framework for assessing University research includes impact case studies), while producing theoretical knowledge to position one's design consultancy as a "thought leader"-e.g., IDEO or Namahn-may be part of a marketing strategy. Nevertheless, we maintain that some difference between these two sets of communities generally stands, as impact on one side and theory production on the other side remain secondary drives. An example of this difference is offered by Wolf et al., who have argued that design at $\mathrm{CHI}$ is a "black art" that researchers do not account for with the same rigour as designers do, or as researchers do when discussing methods [61].

Familiarity with the contours of this gap is essential for developing engagement strategies that strive to increase awareness and use of $\mathrm{HCl}$ theory by UX practitioners. The lack of use of $\mathrm{HCl}$ theory [48] has been attributed not only to theory not being directly applicable to UX practitioners' research and design activities [24, 48]-which motivates the bridging strategies discussed here-but also to the fact that $\mathrm{HCl}$ research "has not been grounded in and guided by a sufficient understanding and acceptance of the nature of design practice" [56, p. 56].

\subsection{Translation as a strategy for bridging the gap}

Several strategies for bridging the gap have been proposed under the broad label of "translational" activity $[40,11,12]$. Translation has been described [15] as a process whereby new forms of knowledge are created. Translational science-a term predominantly found in biomedical research traditions-generally aims to create applied knowledge for the benefit of non-research professionals; for example, General Practice doctors in the case of medical translational science.

There has been a series of proposals for forms of translations of $\mathrm{HCl}$ theory to design practice in particular. A first list is provided by Rogers who offers a pluralistic account: that theory may inform design indirectly through "methods, concepts, frameworks, analytic tools, and accounts" [48, p.129]. Stolterman expands this list and, based on his account of design practice, describes a series of "forms of design support" that "design practitioners are inclined to appreciate and use", including "precise and simple tools or techniques" and "frameworks that do not prescribe" [56, p. 63]. It is often unclear in these accounts, we note, what kind of design practices are intended as the target of $\mathrm{HCl}$ theory (e.g., contrast, for example, the 
practices of product designers in industry with the practices of critical designers in $\mathrm{HCl}$ research).

Colusso and colleagues [11] have started by suggesting that existing translational resources include "implications for design" sections at the end of $\mathrm{HCl}$ papers, and ideation card decks. Implications for design have been classified by Sas and colleagues [51] into four categories, "short descriptions" of findings, "prescriptions" for implementation, "abstractions" of technology features, "sensitizing concepts", and "instantiations" of abstract concepts. Ideation card decks include translations of $\mathrm{HCl}$ frameworks like the one we are addressing below, such as the "tangible interaction framework" [29] and the "exertion framework" [37]. Colusso et al. then proposed a new set of guidelines for creating translational resources, including illustrating findings and theory through examples and data excerpts, rephrasing "implications for design", and integrating $\mathrm{HCl}$ knowledge into existing UX practitioner tools and resources.

\subsection{Translations as "intermediate-level knowledge"}

All the resources proposed above are arguably more concrete than the original theoretical knowledge they are supposed to translate. In that sense, they constitute what Höök and Löwgren [28] have labelled as "intermediate-level knowledge" which sits somewhere below theory and above design instances (or, in a later presentation of this knowledge taxonomy, between "general theory" and "design artefacts" [35]). The types of resources that proponents of this classification fit within the space-including methods and tools, concepts, guidelines, patterns and annotated portfolios-mirror the list of potential translations that we have given in the previous section. They also share the common goal of seeking to inform the design of artefacts. Hence in this schema, translations of $\mathrm{HCl}$ theory probably inhabit the "generative intermediate-level knowledge" space presented in Figure 1 (coloured in grey) that we return to and extend later on.

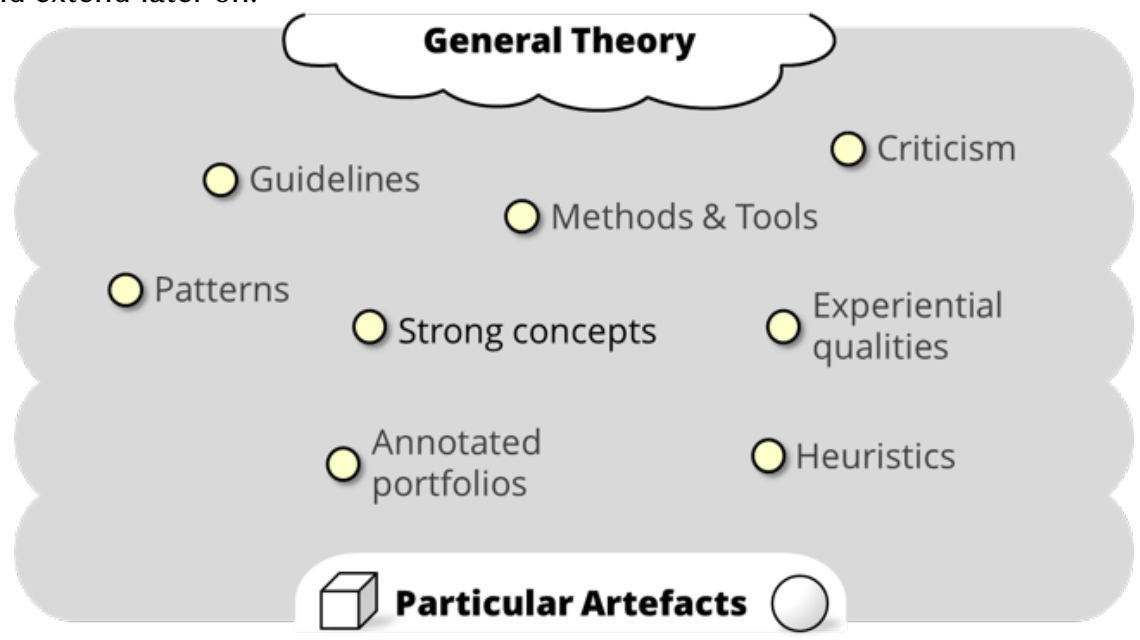

Figure 1: Intermediate-level knowledge space in between general theory and particular artefacts; adapted from $[28,35]$ 


\section{A CASE STUDY OF TRANSLATING HCI THEORY INTO UX PRACTICE}

Often it seems that discussions about theory in $\mathrm{HCl}$ and its relationship to practice tend to be conducted in the abstract. In contrast with these prevailing tendencies of the discourse, we now present a series of concrete translational interventions which were conducted in partnership with a large UK-based media organization that produces and distributes video, audio and interactive content both online and through TV and radio broadcasting-we will call them 'MediaOrg'.

MediaOrg is a major public sector broadcaster with a long history of pioneering both technologies and content for radio and television before moving their attention into digital content including web, mobile and streaming over recent decades. They operate and create content for multiple television channels and radio networks, provide dedicated platforms for streaming catch-up television and audio, and run an extremely popular website. Their content covers news, sports, factual, drama, children's and education and they export content worldwide. Significantly for this paper, they support a UX division of two hundred UX practitioners. This multi-disciplinary team spans designers, writers, researchers, information architects and accessibility specialists who apply a human-centred approach to the design of MediaOrg's digital experiences. The UX division has a matrix organisation, with vertical teams of UX designers embedded into specific product groups within the organisation, while specialist practices such as design research, UX writing, UX architecture and accessibility weave horizontally across products. MediaOrg also runs a significant and separate R\&D division, also of just over 200 researchers, including engineers, ethnographers and designers whose work spans the broadcast chain from broadcast technologies to $\mathrm{HCl}$. This division is seen as a centre of excellence for broadcast R\&D and routinely engages with Universities though joint projects, participation in national and international research programmes, support for PhD students and hosting visitors, as was the case in this paper.

\subsection{The context}

The partnership between ourselves and MediaOrg on this particular translation project began in 2011, although in some ways set against the backdrop of an existing relationship to the organization which predated this. Our group had collaborated with MediaOrg on a variety of projects since the 1990s and so already benefitted from a network of relationships within the organisation and we also routinely encountered members of their R\&D team (though not the UX team) at conferences and other academic networking events. In particular, the artists and artistic projects that inspired the trajectories framework would have been known to members of the R\&D team and it is likely that they would have encountered the concepts through the literature and various early presentations and conversations at events. In 2011 Benford (coauthor) was awarded a 'Dream Fellowship' by the UK's Engineering and Physical Sciences research Council (EPSRC) to buy out his time so that he could undertake a dedicated programme of impact activities aimed at deepening connections with the creative industries. This led to an approach to MediaOrg to see whether they would host him as a 'Visiting Professor' to be based in the R\&D division, with part of the brief being to explore potential applications of trajectories thinking throughout the wider organisation, especially within the UX division. Benford was accompanied by a current PhD student who undertook a parallel 
three-month internship at MediaOrg, and ultimately by a second (Velt - co-author) who was sponsored by MediaOrg specifically to work with them on translating trajectories. The extended series of visits by all parties that took place over a period of roughly a year provided us with inside access to people and projects and so established the platform for the activities described below. With hindsight, the engagement of both a Professor who could champion the vision of trajectories with research and UX managers and PhD students who could directly work on MediaOrg's projects turned out to be important for getting practitioners to care about the translation of trajectories, operating as a kind of 'pincer movement'.

MediaOrg invited us into their organization and repeatedly demonstrated a strong a desire to draw on the trajectories framework to inform their design and UX work. This desire ran across multiple divisions of the organization-including the aforementioned UX and R\&D functions, but also a product group. On their invitation, we became involved in ongoing projects, meeting with board level members of MediaOrg, and at one point being hired as consultants. This led us to cultivate and document a varied palette of approaches to translation.

Ultimately the trajectories framework was mutually chosen because MediaOrg believed it to be a theory that offered them traction for the design of their media experiences, as well as offering a way to address challenges in the joining up of the often-fragmented nature of user experiences of multiple services. It was thought-by them as well as by us-to be the right theory for the specific needs of the organization.

Naturally, this partnership was also driven by particular motivations on the academic side. As researchers-at least in our (UK-based) research culture-we are increasingly called to account for the impact of our research by the bodies that fund us (a desire to "package theories and methods for industry/wider use" [17]). Trajectories are also part of a broader current in $\mathrm{HCl}$ that seeks to identify and express theoretical and conceptual constructs that have generative ambitions, and to our knowledge there is a lack of work fulfilling these ambitions in industrial settings. In short, there was and is a set of motivations for us (and we suspect many other researchers) to seek possible translations of our research into UX and design practices.

\subsection{The trajectories conceptual framework}

All of the (five) interventions ${ }^{3}$ we detail in the following sections shared the same goal: connecting stakeholders with the trajectories conceptual framework and seeking its use-in some form or another-within MediaOrg's design and production processes.

Briefly put, the trajectories framework (see Table 1 for summary) provides a set of concepts to describe interactions in cultural experiences as journeys that span hybrid dimensions in space, time, roles, and interfaces. Its three key concepts are canonical (scripted), participant (actual) and historic (recounted) trajectories which are then broken down into various subconcepts. As mentioned above, the framework was partly chosen because of the researchers' desire to see impact from a substantial piece of academic research while MediaOrg saw potential in it as a "joined up" approach able to address the challenges of delivering multiscreen content. Although the framework has received substantive engagement in $\mathrm{HCl}$ research communities, it also was intended-aspirationally, perhaps like much $\mathrm{HCl}$ research theory and design frameworks-to provide for various kinds of practitioner uses.

\footnotetext{
${ }^{3}$ An extended account can be found in Velt's PhD thesis [58].
} 


\begin{tabular}{|c|c|}
\hline $\begin{array}{c}\text { TRAJECTORIES } \\
\text { FRAMEWORK TERM }\end{array}$ & MEANING \\
\hline Canonical trajectory & Designer-intended version of the user journey \\
\hline Participant trajectory & Actual user-experienced version of the journey \\
\hline Historic trajectory & Retold or reconstituted version of the journey \\
\hline Transitions & $\begin{array}{l}\text { Points where continuity of the experience is at } \\
\text { risk in some way, including: beginnings, } \\
\text { endings, role transitions, interface transitions, } \\
\text { episodes, seams in the technical infrastructure, } \\
\& \text { real-virtual transitions }\end{array}$ \\
\hline
\end{tabular}

Table 1: Trajectories vocabulary summary

Within the space identified in Figure 1, trajectories sit towards the top: as discussed by Velt et al. [58], they are either a form of theory or at least a high-level set of strong concepts. Their expression as a conceptual framework is firmly grounded in $\mathrm{HCl}$ research and in academic publications $[1,3,4]$, and has been described as an example of contemporary $\mathrm{HCl}$ theory by others [49]. More recently, trajectories has also been the subject of a survey which showed it to be widely known within $\mathrm{HCl}$ research and used by researchers for design purposes, but with little evidence of use in non-academic design practice [58]. In line with this set of prior research, we analyse our various translations of trajectories-as documented in the interventions below-in relation to the two-dimensional gap outlined by Höök and Löwgren $[28,35]$.

The interventions involved different ways of configuring translation work between us and our partners. The translation work itself arose practically from embedding both a senior researcher (Benford) and a PhD student (Velt) within the organization for substantial periods of time during which various approaches were tried. Early on, the process was driven by us as $\mathrm{HCl}$ researchers whose aim was to introduce the framework to various stakeholders within MediaOrg, but soon became more opportunistic, with our research team responding to opportunities to try trajectories in practice as they arose in our interactions with MediaOrg. In the following, we present these experiences as a series of distinct interventions, roughly in the chronological order in which they unfolded, although in practice they were somewhat more interleaved than this.

\subsection{Intervention 1: From seminars to pathways projects}

As part of his visiting position within MediaOrg, Benford undertook a series of meetings with various stakeholders spanning R\&D, the organization's UX design practitioners and departments focused on learning and sport. Benford also employed trajectories to analyze two of MediaOrg's ongoing multiscreen design projects, and as part of this work producing two zoomable trajectory diagrams constructed using the non-slide-based Prezi zoomable 
presentation tool ${ }^{4}$, the outputs of which were made available online to the organization at large, coupled with a report (see Figure 2). Following this, MediaOrg hosted a workshop to introduce trajectories to various relatively senior staff within the organization, including undertaking a short paper-based modelling exercise of their own. Benford also produced an internal blog post and video describing his experiences during the visiting position.

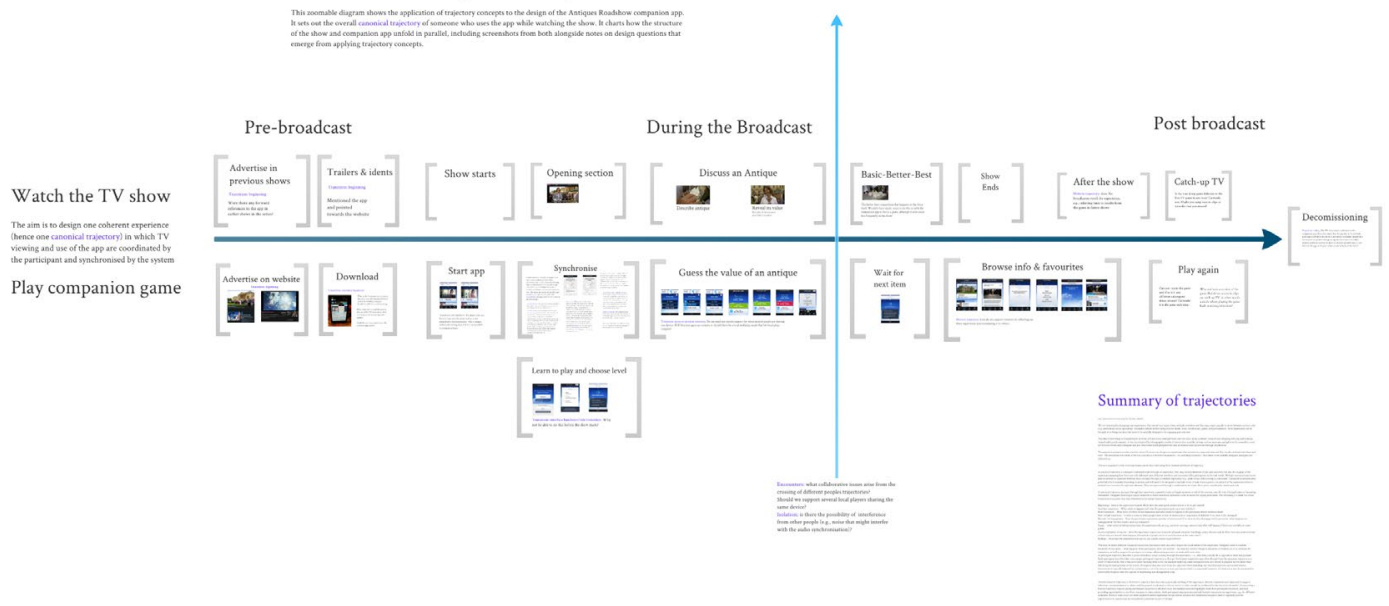

Figure 2: The companion app to one of MediaOrg's shows, analysed as a canonical trajectory and published as a zoomable presentation (created by Benford with Prezi)

These activities led to the chief design director of MediaOrg arranging a further seminar to be delivered at the annual away day for staff. Months later, we learned that the design director had created a position titled "pathway producer", and had tasked the position holder to commission projects labelled as "pathways", a term that both the design director and the position holder saw as a translation of "trajectories". We interviewed this person and attended a project meeting to understand how that translation had been conducted by the organization itself (since we were aware that Benford's initial visit had led to a range of other activities within the organization that had begun to fold in trajectories concepts). We learned that the design director had introduced trajectories as a "UX method or technique" and as a way of "commissioning experiences" globally rather than at "product level". The director also renamed the high-level concept of trajectories to "pathways", since they deemed "trajectories" as "too academic". The use of this term as a replacement for "trajectories" began during an internal presentation: "there was already a well-understood description of" the journey through experiences that trajectories constitute, which was named a "pathway"-we also note a possible connection with the UX concept of user journeys [36] but perhaps most obviously the broader UX discourse of "user pathways". On the other hand, the pathways producer themselves considered trajectories as a way of aligning teams with different "cultures", namely online and broadcast program producers, and tried to consolidate it as a production process model.

${ }^{4}$ https://prezi.com 
An important aspect for the development of the "pathways" notion was that it addressed specific organizational needs: specifically, for bringing a sense of designed coherence to content that MediaOrg had the ambition to span "vertical" products and departments. Notions of "pathways" also corresponded to internal studies that had been commissioned to analyse how online users engaged with content spread around website sections corresponding to these products and departments. In this sense, we see that translational activities are intertwined with organizational matters. In spite of our initial interests in translating all of the concepts in the framework, for MediaOrg, working to make the translation systematically align with the entire original contents of the trajectories framework was simply not a priority, as stakeholders were "outcome-focused" and cared more for "velocity and collaboration" than for "methodological detail" and "rigour" (the design director's account).

The concrete outcomes of this particular intervention resulted in a specific contribution to MediaOrg's long running interests in broadcasting music festivals. This included delivering a pathway which would lead music festival fans, both on-site and online, to engage with MediaOrg's content. Thus, this particular intervention involved commissioning a portal aggregating content from multiple website sections, as well as a communication strategy both at festival locations-with a dedicated space at festivals where the organization has already planned to be present and where wristbands advertising the specific campaign were handed out-and online, with social media accounts, user-generated content, and videos being commissioned (see Error! Reference source not found.). Some of these assets were created by departments within the company, and some-including the portal and the visual identity of the project-were sub-contracted. To support this, the company provided a "storyboard" which described the global trajectory or pathway of a single user. Although the final experience differed significantly from the storyboard, it was nevertheless used to convey a global dynamic that formed the core of the project. And it is by this somewhat convoluted and complex route that trajectories came to be located in specific practical circumstances within MediaOrg.

\subsection{Intervention 2: From seminars and zoomable diagrams to trajectory templates}

Drawing on the work performed during Intervention 1, we were commissioned to organize two further workshops to help MediaOrg ideate scenarios for another part of the organization, this time concerned with learning (one of the key remits of MediaOrg is pedagogical). The coorganizers of the workshop were the members of a department whose main focus was the development of online educational content. Their primary interest in this case was how to integrate MediaOrg's own content with external content, locations, and other learning opportunities, to create long-term and joined-up learning experiences-ideal testing grounds for trajectories concepts. Of the five scenarios iterated in the workshops, none directly corresponded to existing projects being commissioned, but rather to areas that the department might pursue over the coming years.

On the first day of the workshop, the scenarios-or, in the framework's terms, "canonical trajectories"-were developed and written up on large posters as user-centred narratives describing interaction over time, and paired with "personas" [42] describing the person or group going through the experience. The second day of the workshop, a month later, involved refining the scenarios by considering concepts from the trajectories framework. This part of the workshop was divided into short sessions, where each group of participants would address a subset of the framework, then report on how these concepts were translated into the design of 
the scenario, producing maps of the user trajectory, as shown in Figure 3. Following these workshops, stakeholders asked for our help consolidating these scenarios into "commissioning templates" that could then be used in the development of new media experiences.

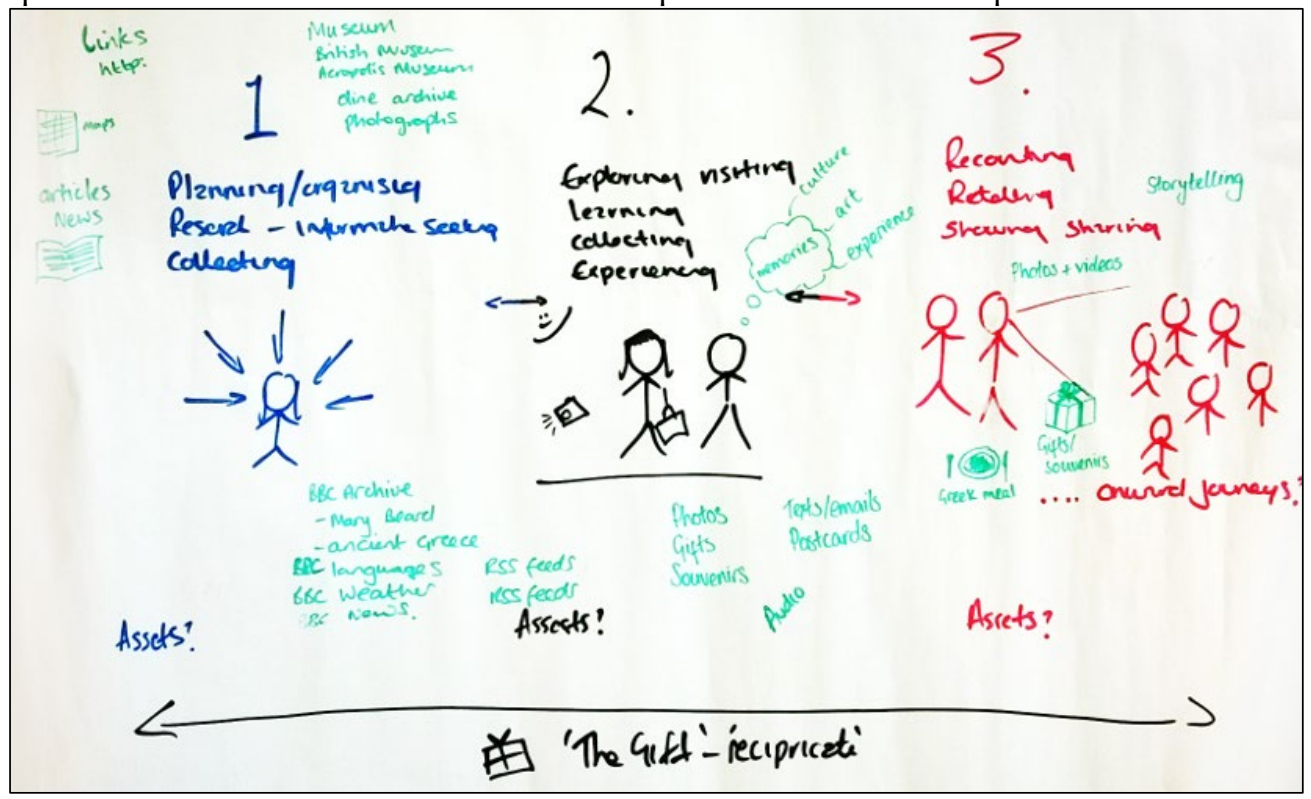

Figure 3: A scenario describing a gifting experience, produced as part of trajectory workshops

This process was expected to produce forms of knowledge that would help producers commission future projects-which stakeholders expected would be grounded in "academic rigor"-revealed some differences in goals. As $\mathrm{HCl}$ researchers, we were looking for commonalities and differences between scenarios from the point of view of the user experience, seeking to validate or help refine the concepts in the framework. Our industrial partners, on the other hand, were trying to identify specific assets-technology and content-that they would have to commission to support the concepts developed in the workshop.

Other debates included whether we should follow a "depth-first" strategy, starting with the refinement of a single scenario in detail, or a "breadth-first" strategy in which we iterated all scenarios simultaneously. Each approach pointed towards a different potential outcome. In one case, the design outcome would have been to commission a full "trajectory", that is an experience involving multiple interactions spread over interfaces. In the other, the ideal outcome was to prototype one or more technological solutions corresponding to a small part of a trajectory, but mapping to several scenarios at once. In the first case-in line with characterizations of trajectories as an example of $\mathrm{HCl}$ research that considers "activity as the ultimate particular" [60]-the primary focus of design is on what users do when interacting with technology, while in the second case, it is on the technology itself.

\subsection{Intervention 3: Translating trajectories into cards}


The third translation was initiated by MediaOrg themselves and involved translating the trajectories framework into a set of ideation cards, a common kind of resource within both $\mathrm{HCl}$ research and industrial UX and design working practices (see [14] for a review of various types and studies of such cards). To this end MediaOrg commissioned two staff from their R\&D division to create new ways of "illustrating trajectories". They were given a copy of the original trajectories paper [4], as well as a report we had produced compiling a variety of sketches and zoomable diagrams that offered practical examples of trajectory diagrams and concepts. To support their work, they also met with colleagues from other departments and conducted informal observations of their design processes, which relied heavily on personas as a technique to embed audience-centric concerns into the process.

After two weeks, the R\&D team presented a set of cards, each representing one aspect of an overall trajectory experience, for example a device being used, a location being visited in the course of that trajectory, or an asset created by MediaOrg. These cards were designed to offer a mechanism for capture information about how they were used. Each card contained a Mifare NFC tag. A mouse-sized reading device was developed with which card users would tap cards one after another and record this sequence.

In the intent of MediaOrg's developer, this recorded sequence would constitute a trajectory through the design space that could be replayed using presentation software that was widely used within the organisation. Following this first proposal, one of us (Velt) was invited to support MediaOrg in refining the prototype. This resulted in further improvements to the playback interface, while an R\&D employee worked on defining the set of cards and identifying potential users within the company.

Velt's refined prototype included two more options for capturing trajectories based on the cards, either by manipulating representations of cards on a web interface, or by using computer vision to record the position of all cards from a photo of a table or poster. The cards themselves were divided into six card suits:

- Participants, corresponding to named personas.

- Places, listing the locations where participants would access MediaOrg's content (in yellow in Figure 4).

- Activities participants would do while accessing content, including those related-e.g., watching a film-and unrelated-e.g., running or working-to this content.

- The devices they would use to do so (in blue in Figure 4).

- The channels involved, which include MediaOrg's own TV, radio channels, and online services, as well as related third-parties such as social media (in red in Figure 4).

- Units of content, for example individual news stories or film franchises. 


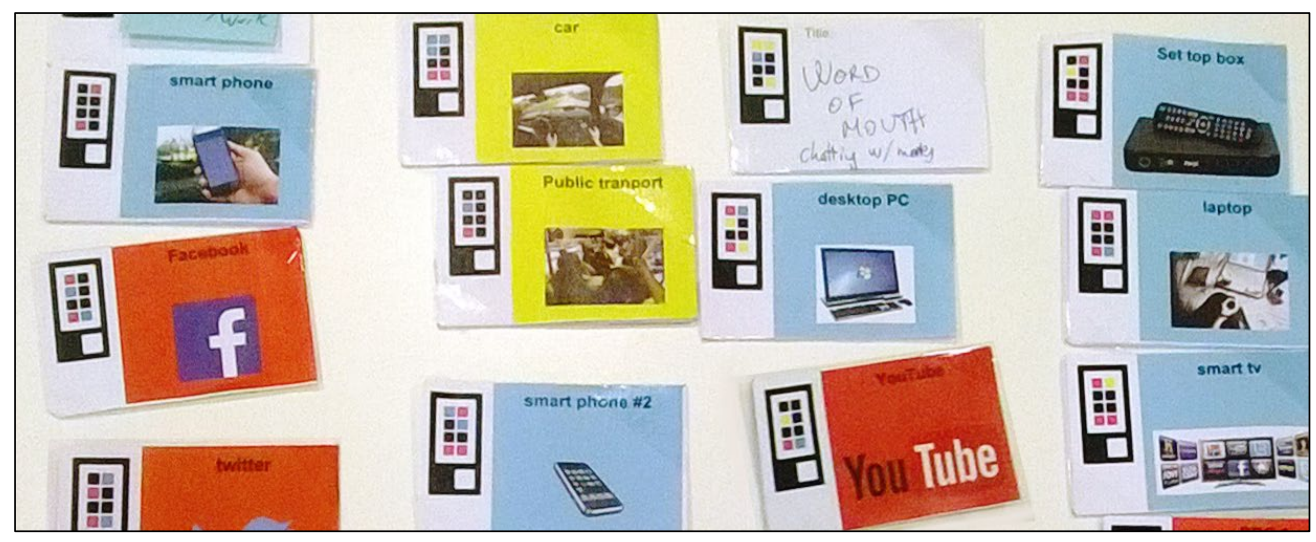

Figure 4: Examples of trajectory cards

These card suites were intended to describe the dimensions of users' experiences and aspects of them were clearly informed and shaped by the material of the trajectories framework. In our view these dimensions of users' experiences can be mapped to a part of the trajectories framework that has been labelled as the "hybrid dimensions of experience". This refers to the description of the design space for complex cultural experiences as spanning hybrid time, hybrid space, hybrid roles and hybrid interfaces. At the same time, the design card implementation also refines the trajectories framework's original classification of space, time, roles, and interfaces in interesting ways. In the language of trajectories, roles are now split between describing who people are and what they do. Interfaces are split between the hardware used to access content and the commercial service that provides it. The suite of cards offering various "units of content" doesn't map with trajectories, which is unsurprising because the original framework was derived from descriptions of experiences that only involve a single narrative. Further, time-temporality being a key element of trajectories-is not expressed through the cards themselves, although in all demonstrations, we physically grouped cards according to temporal divisions.

As we presented the prototype internally to MediaOrg, two main use cases emerged. The first one, similar to the workshops described in the previous section, was to use cards to support the design of new experiences. In that use case, the sequences of cards would represent the ideal experience, or "canonical trajectory". On the other hand, many UX designers and researchers in MediaOrg were interested in the potential of the cards to analyse or describe the existing behavior of their media audiences or, in the framework's terms, the "participant trajectory" of these audiences. In that second use case, the cards would act as a dynamic complement to personas, widely used within the organization.

\subsection{Intervention 4: Using the trajectory cards in practice}

Intervention 4 built directly upon Intervention 3, in that we conducted an evaluation of the newly designed trajectory cards by bringing them to the context of MediaOrg's design processes. To this end, MediaOrg identified a candidate project that was selected because it combined two challenges pertinent to their present concerns. First, the project concerned 
young audiences, which MediaOrg considered hard to reach due to young peoples' complex media consumption patterns. Secondly, the project involved moving participants across to web resources provided by partner organizations, which MediaOrg was not used to doing and felt that trajectories, in the form of design cards, could support thinking around this.

The candidate project was an online personality quiz, the primary purpose of which was to convince teenagers that there are jobs in the technology sector that suit everyone's profile and tastes. Another goal was to promote online resources to help audiences develop their knowledge of technology. These resources were provided by partner organisations and curated to match the profiles from the personality quiz. With MediaOrg, we conducted two ideation workshops, four months and two months before the release deadlines. To prepare the first workshop, we presented the cards to the project's producer, then asked them whether there was a need for extra cards to be added to the deck that would be specific to the project. We created two new sets of cards, one to describe the target resources that audiences were brought to, and one describing a segmentation of audiences based on an internal report.

Workshop 1 was attended by three producers from the same department, two of which were directly working on the project, one $R \& D$ researcher and one of us. Rather than setting up a clear format for the workshop upfront, we explored two ways the cards could support design and project planning: discussing the interaction design of the quiz itself and discussing the marketing strategy through which audiences would be reached. The first route was quickly dismissed: producers felt that, because there were too many unknown dimensions at that stage in the project, they couldn't use the cards to describe their design in a way that was meaningful. In particular, one of their main concerns was to match audience characteristics to resources provided by partners, and they only had a vague idea of what these resources would be.

Most of the workshop time was spent discussing the "on-boarding journey", in other words, finding out strategies to market the product to the target audience. The process was iterative, and involved creating several strategies based on internal reports describing the segmentation of the audience. The use of the cards was both analytical-a discussion of what the current behavior of the audience was or, to use the taxonomy of trajectories, the participant trajectory-and generative-a discussion of what the project would lead audiences to do, in trajectory terms, this would be the canonical trajectory.

Workshop 2 on the other hand was devoted to refining the details of this on-boarding journey by identifying specific content and channels for implementation, such as via social media.

Feedback regarding both workshops was generally positive, and the producers acknowledged that they based important decisions on reflections developed during the workshops-including broadening the target audience, and a more thorough consideration of audience characteristics. However, the specific strategy that was designed during the two workshops was not developed, mostly for organizational reasons: most of the recommendations fell outside the remit of the producers. From the point of view of the researcher involved in the project, it felt that the aspects of the workshop that were most directly related to trajectories were not actually carried on to the final product. In other words, it would be unrealistic to affirm that the trajectories conceptual framework had a direct impact on shaping the outcome of the project.

It is worth noting that of the workshop participants, two had no knowledge of the trajectories framework beyond the cards themselves, and that using the cards didn't lead to 
consider the broader contents of the framework. In other words, it was clear in at least their cases that while trajectories informed card development, "reverse-engineering" the cards back to trajectories was probably not possible. However, we used our own knowledge of the concepts and our position as workshop facilitators to flag up design issues corresponding to the framework. In this sense, trajectories informed the process in a unidirectional manner.

\subsection{Intervention 5: A UX Professional interprets the framework}

During our long-term engagement with MediaOrg, one of their UX designers attended a trajectories workshop held at our University. He described his position being Creative Director for User Experience Architecture, leading a team of information architects committed to making the organisation's tools, content, experiences and platform more meaningful and connected. He was subsequently inspired to employ the framework within his own practice, ultimately publishing a pamphlet that translating its concepts "for UX designers" [43]. The framing of trajectories in this pamphlet was heavily inspired by principles from Information Architecture, a discipline overlapping with (and perhaps in some accounts, encompassed by) UX, as well as information science and architecture. The pamphlet was posted on his blog and also provided the basis for a series of presentations at UX community conferences.

His presentation of trajectories often drew on everyday metaphors to help explain the concepts and employed a distinctive hand-drawn sketching style (see Figure 5). Overall, the pamphlet provided a complete translation and explanation of the trajectories framework, introducing all of its concepts and largely sticking to the original terms, though with two notable exceptions: canonical trajectories were renamed to be "designed experiences" (see Figure 5) and participant trajectories were renamed to be "individual trajectories". The pamphlet also covered other key trajectory concepts, especially various types of transitions (beginnings, endings, roles, episodes, seams, and access to resources. Notably, the interpretation of the transition between the physical and virtual aspects of experience was extended: "In the original conception of trajectories there was a transition called 'physical/ virtual traversals" "... "However, I think for most information architects we can extend our focus to consider any switching between domains - whether this is a virtual/physical traversal or moving between differently oriented information architectures."

Of particular relevance to this paper, the author was explicit as to how he saw the role of trajectories in UX design, articulating five primary uses and directly relating the framework to existing UX design concepts and methods:

- Bridging gaps in the design of user experiences: noting that trajectories provide "a design and storytelling technique that should help you design better experience by bridging gaps - whether they're between team members during the design process, between iterations of a design as it evolves or within individual designed experiences." He made an explicit contrast with storyboards where "sometimes the secrets of a design are lost in the gutter between the cells."

- $\quad$ Supporting co-design with users: "It's really just a language to describe experiences combining some specific terms and a rough style of sketching a diagram" and noting that "once you've described the basic idea of tracing the story of an experience across a two-dimensional line, everyone can do it". However, he also noted the importance of "avoiding using the technical jargon of Trajectories with the participant". 
- Extending domain modelling: "Most domain models are graphs - nodes and edges boxes and arrows. Using some of the ideas of Trajectories should enable you to tell stories through the models you create, validating the models you create with domain experts and sharing the insights you've acquired with other designers and team members."

- Reflecting on organisational design processes: "There's one other application of Trajectories that I'd like to introduce - I've called it "organisational trajectories'" and commenting "this is another example of why Trajectories are so important. If you've used stories to describe the requirements of the design and the imagined experiences that it will power, there will be a more detailed shared understanding of how the design works."

- Envisioning possible futures: "Any design team or organisation can project trajectories into the future to begin to describe the shape of things to come. What possibilities might stand in the future? What threats could undermine your design?"

We note that, as was the case in intervention 1, language was an essential part of developing this new material. Words like "encounters", "transitions" and "historical trajectory" have been mostly kept intact (though with sometime slightly extended meanings), while other words are not even mentioned ("canonical trajectory"). Although the Creative Director doesn't discuss vocabulary choices in his pamphlet, he concludes it by a reflection on how trajectories should be used as part of a language of design towards "creating and facilitating shared meaning".

As a final connection in the story, we subsequently drew on this account of trajectories and document to teach the framework to our own students as part of a Masters level module of 'Mixed Reality Technologies' taken by both Computer Science and $\mathrm{HCl}$ students.

\section{The designed experience.}

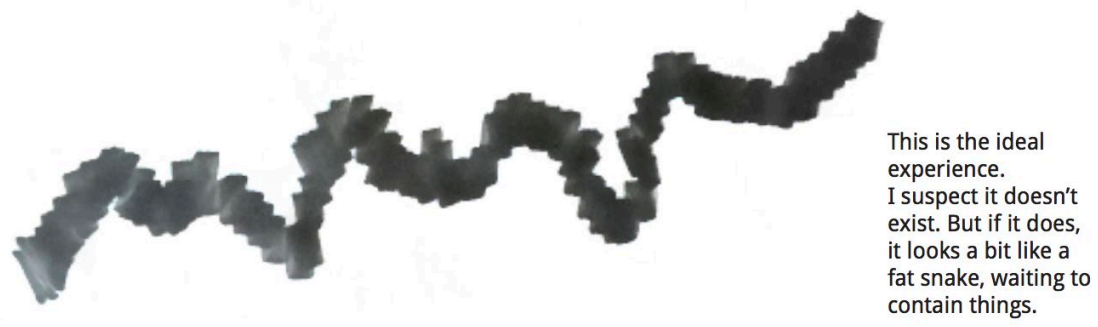




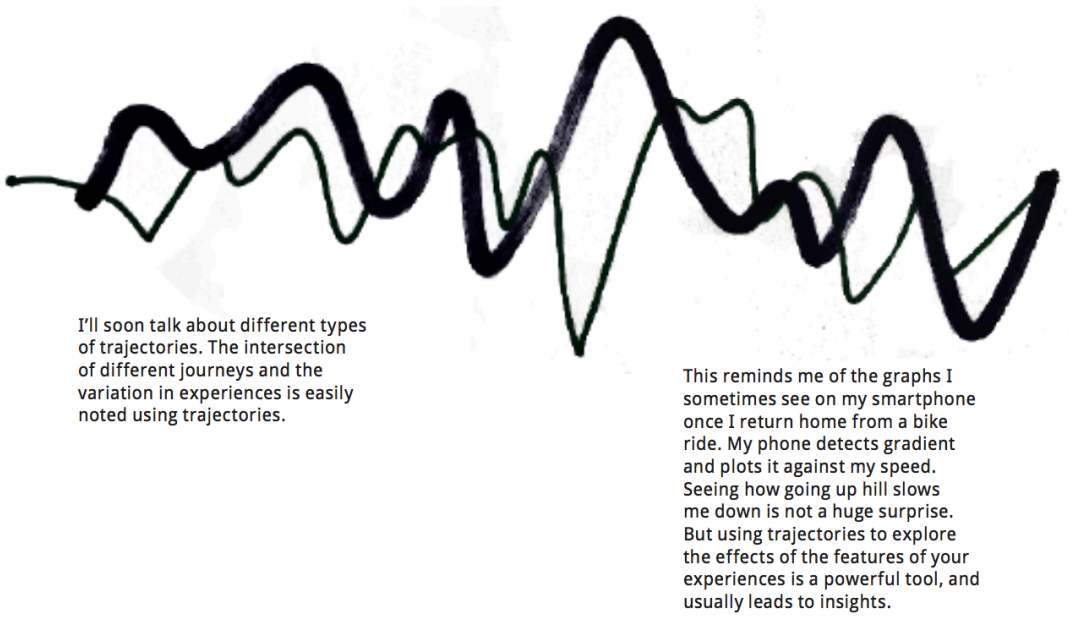

Figure 5: Two examples of interpreting trajectories taken from Information Architect Dan Ramsden's booklet [43]

\section{REVISITING THE GAP BETWEEN THEORY AND PRACTICE IN HCI}

We have presented a range of different translations of trajectories in practice through a series of interventions mutually undertaken between ourselves and MediaOrg. At this point we now turn to reflect on how these experiences relate to HCl's apparent 'gap' between theory and practice and its conceptualisation as revealed by our earlier literature review.

\subsection{The nature of the gap}

We begin by charting the "knowledge space" where the various attempts at translation might be located. As part of this we choose to articulate the gap between academic $\mathrm{HCl}$ research and professional UX as a matter of differing "practices". We also will argue-via examples of translations-for the situatedness of "practices" within another gap, specifically that between theory and design instances.

We make this distinction for the following reason. It might be tempting to think that the gap between theory and design instances that intermediate-level knowledge fills is the same gap as that between $\mathrm{HCl}$ academic research and the work of UX practitioners. In other words, that $\mathrm{HCl}$ research is concerned with general theory while UX deals in particular artefacts.

However, the literature suggests otherwise, revealing the aforementioned two distinct gaps-or perhaps better a two-dimensional gap.

First, Höök and Löwgren's proposal is entirely situated within one "practice", namely interaction design research, which may either be seen as a design-centered subset of $\mathrm{HCl}$-as evidenced by many examples of $\mathrm{HCl}$ researchers dealing in particular artefacts and adopting 
practice-based methods, under the broad umbrella of Research through Design [63]-or as discipline of its own [18]. Conversely, UX practitioners engage with multiple forms of knowledge mirroring Höök and Löwgren's list, from portfolios, methods and tools, up to the kinds of reflections and abstractions that constitute forms of theory-even if the nature of design-led theories may differ from traditional scientific theories, for example being more contingent [24]. Our characterization of the academic $\mathrm{HCl}$ industry UX gap therefore suggests that both sides of that gap produce forms of knowledge that sit at every level in the intermediate-level knowledge space accounts of Höök and Löwgren.

The examples of intermediate knowledge provided by Höök and Löwgren, and further documented by Löwgren [35] (we note that he does do in a publication that is clearly targeted at both sides of the research-practice gap) mirror some of the forms of knowledge that we've encountered during our interventions: Design patterns and guidelines are published internally within MediaOrg to circulate good practices. Intermediate-level knowledge also includes tools - of which the cards from intervention 4 are arguably an example - and methods - the original end goal of developing these cards was to formalise them into a design support method. Portfolios are presented and discussed within design meetings in MediaOrg and have been mentioned as a way of circulating good practices. Finally, an argument has been proposed that trajectories themselves, by being more applied than general $\mathrm{HCl}$ theory, constitute a strong concept, or a list of strong concepts.

Figure 6 summarizes this "map of two gaps", and provides support for discussing the different translational modes we present next. On the left we see the domain of "Academic $\mathrm{HCl}$ Research" whereas on the right is that of "Professional UX Design Practice" (this, naturally, is a simplification, but is instructive in being so). The two arrows suggest that $\mathrm{HCl}$ researchers have traditionally tendency towards concerns of producing generalizations or-more grandioselytheory, while the work of UX practitioners has traditionally tended towards the production of particular artefacts (in this we naturally include services). We use the slope of the dotted line to suggest that these are by no means exclusive tendencies.

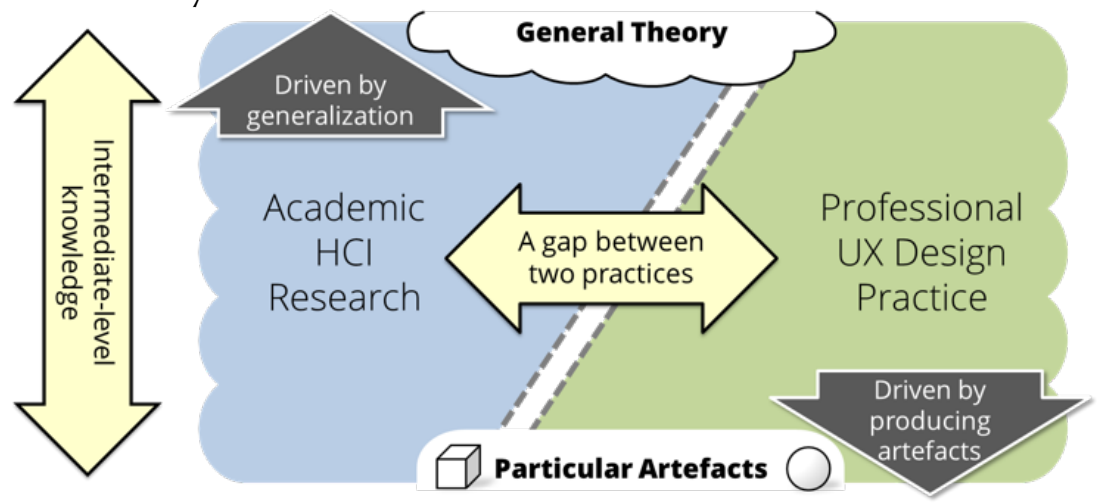

Figure 6: Mapping the dual gap between academic $\mathrm{HCI}$ research and professional UX design practices, and intermediate-level knowledge

Now that we understand something more of the nature of the gap, the next question is what kinds of translations might bridge it? The following, more extensive part of our discussion 
considers how we might start conceptualising different strategies associated with bridging work through translation. To begin we first consider the motivations of "gap bridging" work.

\subsection{Three Modes of Bridging the gap}

It is worth reminding ourselves why there has been a weight associated to notions of "bridging the gap" between $\mathrm{HCl}$ and UX within the discourse of HCl's various academic research communities such as $\mathrm{CHI}$ or DIS. We also acknowledge that large portions of $\mathrm{HCl}$ research may not align with interests in gap bridging nor necessarily agree with our characterization of "gaps" (although we would argue that, when treated carefully, it can be a generative metaphor [1]).

First, it is not uncommon within $\mathrm{HCl}$ to feel that its research should make a practical difference, coupled with a sense of frustration of potential non-use [12]. We feel that this frustration may be borne by and be symptomatic of HCl's constructive tendencies [41] and its history grounded in ergonomics and latterly, usability engineering. Second, there is a sense of the possibility of shared identity between $\mathrm{HCl}$ researchers and UX practitioners. There is a motivation within $\mathrm{HCl}$ to learn from others, and UX practitioners' work-while operating with different matters at stake-certainly orients to an overlapping set of concerns to those of academic $\mathrm{HCl}$ researchers. Thus, in this view, $\mathrm{HCl}$ and $\mathrm{UX}$ may be addressing some of the "same challenges" albeit with different approaches. Third, in the UK at least but no doubt in other countries, there is considerable governmental, funding body, and local institutional pressure to document and demonstrate "impact" in various ways (as we pointed out in Section 3.1). This includes any broader societal impacts of research but also more typical industry application.

These motivations notwithstanding, there are significant challenges to any potential bridging activity. As we have mentioned before, there are different goals for the parties involved, along with contrasting time scales. As such there is no obvious formula to do it-just as there is no single one way to "design" or indeed "do theory". In this sense, we report a model that acts as a reflection of our particular experiences, but one that is grounded in the wider literature we reviewed earlier in this paper.

Here we report on a distillation of this: three "modes" of translation as evidenced by the five interventions reported above. These modes are: 1) $\mathbf{H C I}$ researcher-led translational resources; 2) jointly developed translations that act as boundary objects and 3) UX practitioner-led translational resources. These modes are not mutually exclusive, but should be considered as a continuum that describes a variety of dynamic configurations. Next we describe the different modes, outline the benefits and drawbacks of each, discuss the nature of translation as a compositional activity, and the difficulty of measuring the impact of translations.

\subsubsection{Mode 1: $\mathrm{HCl}$ researcher-led translational resources}

In this mode, it is academic researchers who create translational resources which are then intended to be taken up within design practice. Examples of these researcher-led translational resources include the zoomable trajectory diagram, video and reports and associated seminars and workshops from Interventions 1 and 2 . While primarily led by researchers, our experience shows that these resources can be refined iteratively, based on observations of their use and feedback from practitioners. 
In this mode, practitioners are a group that researchers "represent", as in Callon's definition of "translation" in which he describes how a group of scientists established themselves as spokespeople to/for fishery workers and scallops [7]. Understanding design practice is essential to developing these translational resources, and may involve any of the methods that $\mathrm{HCl}$ researchers traditionally use to understand settings, from relying on readings of literature to conducting ethnographic studies of design practice. It is not the aim of this paper to suggest how much a researcher should know about practitioners' work to correctly address it since that is likely best determined in a case-specific manner-although Gray et al. suggest that only engagement with practitioners and their work "in situ" or "in-the-wild" can help researchers address the "real" rather than the "projected" practice [27].

We can diagrammatize this mode, too. Figure 7 positions such researcher-led translations onto the gap depicted in Figure 6. They are on the left side of the diagram, as they were created within the research community, but closer to the gap they are meant to address than was the case for the original trajectories framework. These resources can cross the gap, either by undergoing further translations-as was the case when trajectories became pathways in Intervention 1-or by being appropriated by UX practitioners, which generally involves changes in the contents of the resources-such as changes in language and revision of concepts that we saw in Intervention 2. The likelihood, even necessity, of such changes has led some $\mathrm{HCl}$ researchers to label industrial uses of their methods-perhaps not without some prejudicial baggage-as "discount methods" [10, 16].

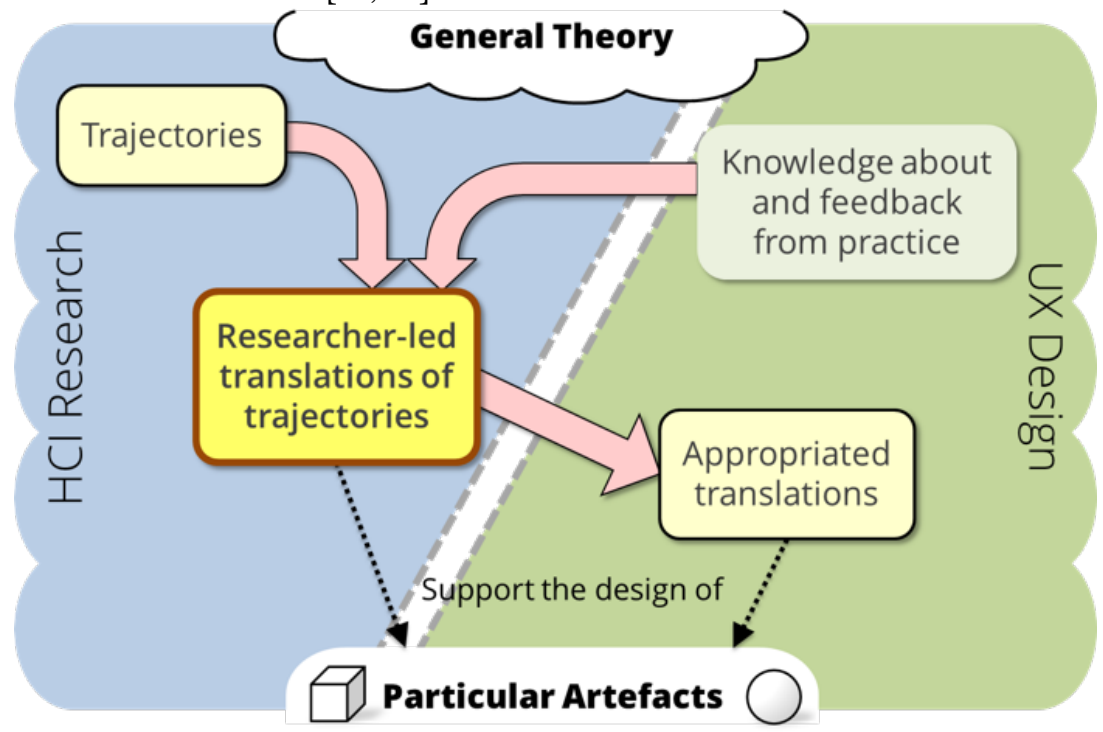

Figure 7: Mode 1, Researcher-led translations

\subsubsection{Mode 2: Jointly developed "boundary object" translations}

The second mode, portrayed in Figure 8, involves the co-production of translational resources, performed jointly between $\mathrm{HCl}$ researchers and UX design practitioners. We suggest that some of interventions 3 and 4 detailed previously in this paper provide examples of this mode with 
instances of translation resources being storyboards, trajectory templates, and ideation cards. From this, we observe that co-produced translations may start from either "side" of the gap: from the research side-for example, workshops leading to scenarios-or from the practitioner side-as with the first version of the trajectory cards.

This joint development, which we label alternatively as a "co-production" or "co-creation" of knowledge, was in our case grounded in ad-hoc relationships between researchers and practitioners. We did not make any of commitment on either side to the values that underpin a large part of our discipline's engagement with co-design, such as the grounding of Scandinavian Participatory Design in workplace democracy [18]. We shared initiative and control over interventions 3 and 4 in dynamic ways and acknowledge that the co-production of knowledge that is described here doesn't require balanced relationships, and our use of the term "co-creation" is closer to how Service-Dominant Logic describes marketing as a cocreation of value between customers and service providers [57].

Co-produced translations can be drawn where the gap is, at the boundary or meeting place between different communities of practice. But do they constitute what Star and Griesemer call "boundary objects" [55]? Firstly we must clarify that there are potentially conflicting views over what sense "boundary objects" is meant by different communities. Design practitioners may use this term themselves in more informal ways to describe a shared objects that are broadly open to interpretation, whereas Star and Griesemer's deployment of the concept is typically-sited within academic communities-used to describe a form of knowledge shared by multiple communities that enable "collaboration without consensus". It is "without consensus" which here is doing the work. We do not simply mean "interpretative flexibility" which is perhaps how "boundary objects" is often taken as a synonym for [54]. It is Star and Griesemer's original notion that is in line with our description of the research-practice gap. As we have established, due to differences of what is at stake, incentives and other motivations (i.e., "without consensus"), "boundary object" describes the inevitability (and perhaps the very necessity) of the "gap". "Boundary objects" were also defined in contrast with Callon's translation, where "the story [...] is necessarily told from the point of view of one passage point” [55 p. 390, emphasis ours]. Both in Callon's original story about scallops, and in translational resources from Mode 1, the point of view adopted is that of academics'. Developing boundary objects instead of simple translational resources therefore means going beyond attempting to "represent" the point of view of design practitioners, by giving them an active part in shaping these resources. There is a sense in which this could be viewed as a form of action research.

We believe the interventions listed above show examples of collaboration without consensus, similar conceptually to a boundary object. First, they enabled communities of practice to do different things. The workshop scenarios were used by MediaOrg to try to identify new projects to commission, while for us as researchers it enabled the building of a taxonomy of trajectories through learning experiences. In turn, the trajectory cards helped MediaOrg's UX design practitioners address their various audiences, while they gave us as researchers access to design processes and acted as a probe. The fact that there was no consensus on what "trajectories" might authoritatively mean-a generative framework on one side, a method for understanding audiences on the other side-didn't get in the way of collaboration as long as both sides were engaged with the resources brokering the relationship.

However, co-creation is not necessarily always stable. Joint focus on particular translational resources that have been developed may disintegrate over time, due to fading interest of one or 
both sides. For instance, in our case scenarios from the trajectory workshops (Intervention 2) stopped being referred to when we all moved to the trajectory cards (Intervention 3). A significant challenge with developing boundary objects is therefore to maintain interest and active engagement on both sides over time. We label this engagement as a form of "active maintenance" of translations. One strategy for fostering this maintenance, is to rely on individuals acting as "disseminating agents" [27]. Within our industrial partnership, a small subset of the stakeholders sensitized to trajectories acted as "champions"-a term they used to describe this role-as they were actively looking for opportunities to use trajectories and its translations across MediaOrg.

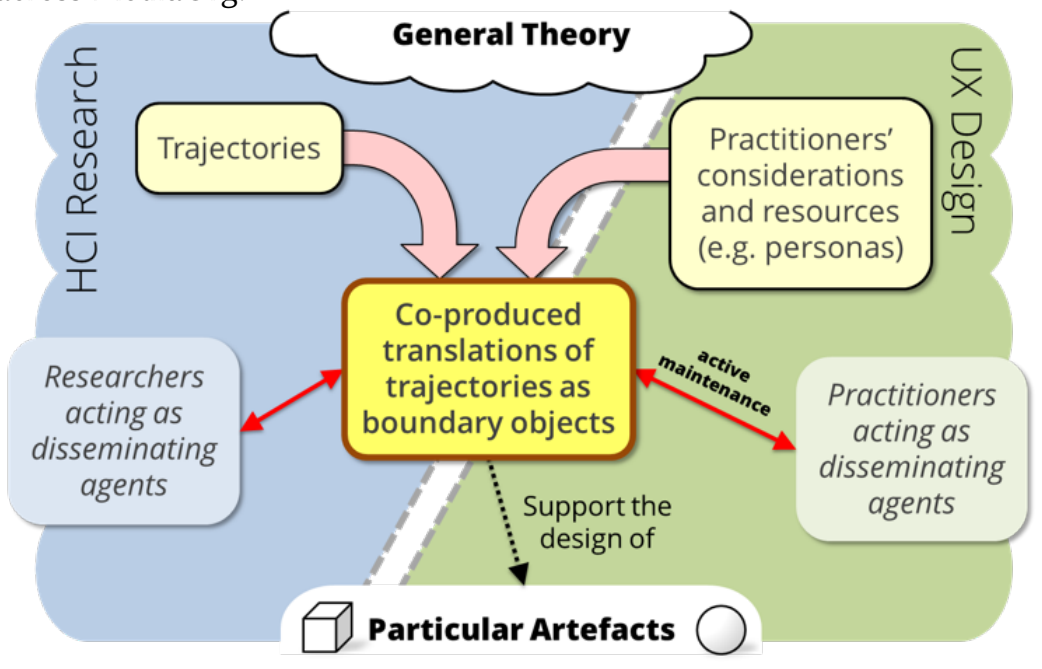

Figure 8: Mode 2, jointly developed translations

\subsubsection{Mode 3: UX practitioner-led translational resources}

Our third mode, that of UX practitioner-led translational resources, is exemplified by Intervention 5. Such translations originate somewhere to the right of the boundary, where practitioners lead translation work themselves, independently of $\mathrm{HCl}$ researchers (see Figure 9). What is notable about our example is the way in which the UX-practitioner independently produced and promoted their own translation of the trajectories framework in a form and using a language suitable for UX designers. In this case, the translation followed an initial twoday long joint workshop in which both sides worked together, so that the genesis of the translation did involve an element of co-creation, but the subsequent translation was carried out, published and presented independently (though with reference to the original). We speculate that other UX-practitioner led translations might be even more decoupled from the original academic researchers, perhaps being inspired by text books, papers, keynotes or other encounters with the original work. 


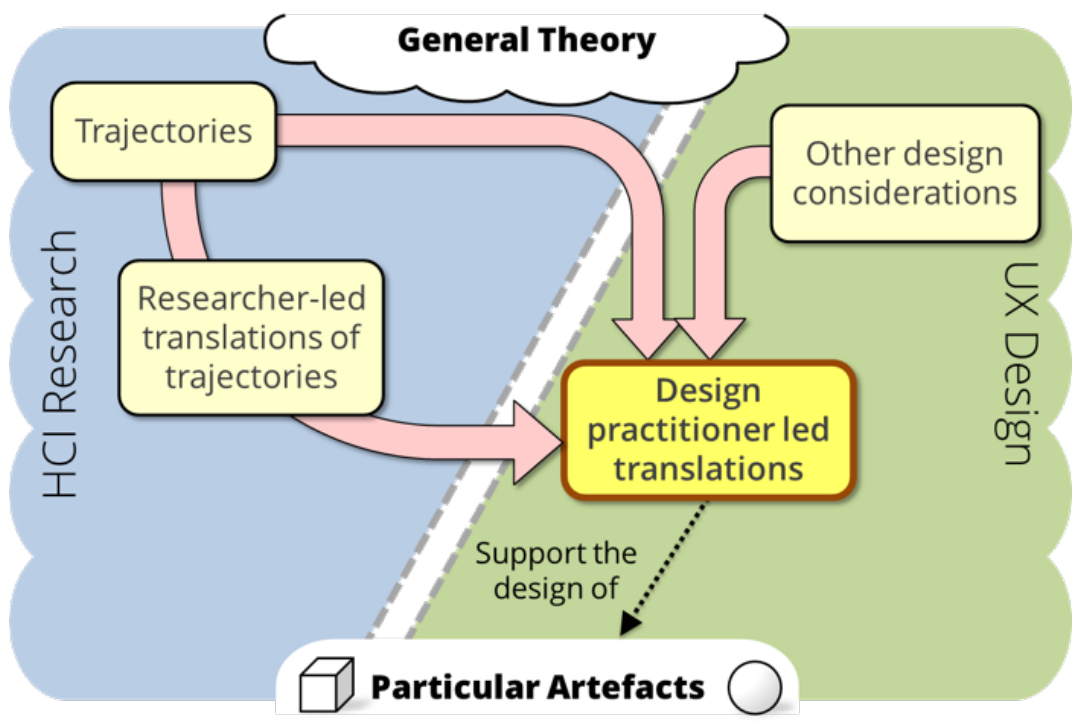

Figure 9: Mode 3, designer-led translations

\subsubsection{Comparing the translation modes}

The three modes of translations present different benefits, drawbacks, and outcomes.

Mode 1's HCl researcher-led approach to developing translations from one side of the gap is arguably faster and involves less concentrated effort. Initially, it requires little engagement from the other side, while in contrast Mode 2's joint process of establishing boundary objects requires significant and lengthy discussions between stakeholders so as to settle on forms of knowledge that both sides would actively engage with (i.e., a form of negotiation). Mode 3 shifts the balance of effort away from $\mathrm{HCl}$ researchers towards UX designers, though consequently the speed of translation is now beyond the control of the former - they must wait to see whether their research is eventually picked up by the UX community.

Mode 1's translations may be refined with feedback from practitioners, but this can be done through occasional, rather than prolonged engagement and thus places less onus on commitment from the practitioner side. Because the active maintenance required for developing boundary objects was time and resource-consuming, it may have only been possible because we as authors were funded via grants where the translation of theoretical $\mathrm{HCl}$ knowledge was either the object of study or one the expected outcomes (thus forming a key motivation and payoff).

Further, Mode 1's translations put $\mathrm{HCl}$ researchers in control, which means they will tend to produce resources where the original framework is still generally recognizable (just as we did). Researcher control in Mode 1 ensures that translations are faithful to what they translate, or at least the sense of what they might decide counts as "faithful" remains a matter for researchers alone. This may be a desirable outcome for $\mathrm{HCl}$ researchers, but also can be the case for UX practitioners: for example, when developing trajectory templates, our partners wanted us to bring in our "academic rigor", which gave license to focus on ensuring translations we were comfortable with. On the other hand, working in Mode 2 and maintaining boundary objects 
such as the trajectory cards requires balancing academic expectations with prolonging collaboration-and involves "tacking back-and-forth" between forms that are relevant to each community and shared forms, a key dynamic noted by Star [54]. Mode 3, involves the least control by academic researchers who do not get to directly influence how their research in translated. While the translation reported in Intervention 5 was comprehensive, largely faithful to the original (in our view), and also credited the original, this need not always be the case. It may be that UX-practitioner led translations diverge greatly from the original research and they may also not reference the research, making it difficult for academics to be aware that they have occurred and take any credit for them.

A potential benefit of Mode 2 lies in the co-creation of design knowledge and the possibility for longer-term engagement that it can afford. By involving the participation of UX practitioners in-situ, Mode 2 mirrors HCl's concern about participation in design-centered research [8] and addresses both its "moral proposition"-the right of designers to be included in the design of the resources they use-and its "pragmatic proposition"-making translations more adapted to actual UX work practices. Mode 2 also seeks to take the sometimes implicit, sometimes explicit claims of design frameworks seriously: i.e., that they distil and make salient conceptual knowledge so that it may better connect with other communities-such as practitioners.

Co-producing translational knowledge, as in Mode 2, results in knowledge that significantly embeds aspects of design practice: the workshop scenarios were directly related to MediaOrg's learning strategy, while the trajectory cards connected both with the widespread use of personas in the workplace, and with the structure of content delivery in terms of channels and editorial domains-e.g., sports and news. This strong link between the boundary object resources and the specificities of workplaces are both an opportunity-they improve the adoption and value of these resources within a workplace-and a challenge that poses a risk to the normative aspirations of academic research-as those challenges may impair the generalizability of these resources outside the organization. For that reason, such challenges draw our attention to the fact that "design practice" is not homogenous, but situated within socio-economic structures [30].

\subsubsection{Translations as composition}

Reflecting more on Mode 3 surfaces the importance of compositional judgement as a key feature of $\mathrm{HCl}$ and $\mathrm{UX}$ bridging work. Translations, where they occur, rely upon something like recombination or mapping of theoretical concepts with other elements. For trajectories, combination involved matching trajectory concepts with similar concepts or vocabulary that have more currency in design practice, such as "user journeys". Mapping, in turn, meant trajectories concepts were transposed to other types of intermediate-level knowledge, such as ideation cards and storyboards. Translations co-produced with or led by UX practitioners also involved mapping trajectories to MediaOrg-specific elements, such as its channels or aligning the framework its specific challenges that were a product of MediaOrg's priorities and strategy.

This logic of combinations and mappings reflect the uses of trajectories by us as academics to produce new conceptual knowledge. This new conceptual knowledge is defined by combining or contrasting parts or whole of trajectories with other concepts, a phenomenon that has been labelled as a "churn in concept space" [58]. We therefore now suggest that this "churn" also includes translational activity and straddles both sides of the research-practice gap. This churn also continues between translations and the production of the ultimate 
particulars of design, as trajectories, or principles derived from the framework, combines with other design considerations. For example, MediaOrg has produced an internal "design framework" of guidelines that cover visual aspects, accessibility concerns, and interaction patterns. We note that this ability to choose and combine multiple considerations into a coherent role, or compositional judgment is considered a key aspect of designers' decisionmaking skills [38], and thus forms a core part of our defined modes.

\subsection{Translations in intermediate-level knowledge}

We now bring all the different modes together as a way of summarising our paper. Taking the model we developed in Figure 6 it is possible to show the logic of translation as composition of other forms knowledge, and express the "churn in intermediate knowledge space" [58]. Figure 10 shows a complex picture where knowledge forms across the whole space inform each other-the arrows we depicted may only show a subset of these relations.

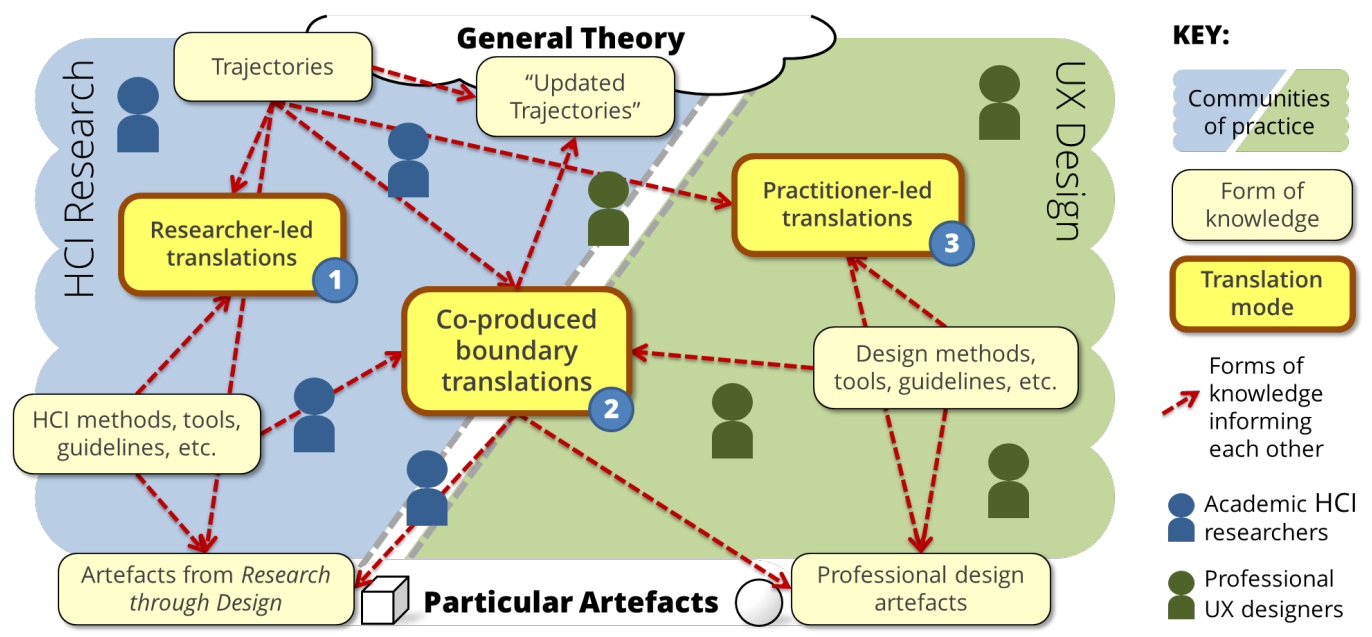

Figure 10: Modes of translation in the intermediate-level knowledge space

All three modes of translation, either led by researchers, by practitioners, or co-produced boundary objects lead to producing forms of knowledge that are part of a broader dialogue that spans the whole "knowledge space". What makes these three approaches different is the configuration of the relationship that we, researchers, want to have with the work of UX practitioners, and with the knowledge that we produce, or co-produce. This leads to our next observation.

Figure 10 also foregrounds the importance of champions or disseminating agents: that is, people-even though they are not of the same nature as translational resources and forms of design knowledge-but nevertheless enable fluidity over the gap. Their willingness to do so-for example, $\mathrm{HCl}$ researchers spending significant time in a different organization, such as a corporation-has been a necessary pre-condition to developing all of the other translational resources that we identified here. There are other ways in which we can also see people as 
translational. Many PhD students, for example, take up jobs in industry and may carry $\mathrm{HCl}$ research knowledge with them. Of course, industry practitioners may also take up jobs in academic research and bring that perspective to universities and related institutions. Then there are those figures previously mentioned who sit at boundaries of both $\mathrm{HCl}$ and UX communities and are influential in both (or "honey bees" [46, p. 28]).

\subsection{Measuring the success of translations}

A major challenge we faced was appreciating the success or otherwise of our translational interventions. Such evaluation may be important, both to judge the relevance of the original $\mathrm{HCl}$ knowledge as well of any translational resources, but also increasingly as part of the wider research landscape. For example, as we have indicated earlier in this paper, a significant element of the UK's national research assessment exercise (e.g., "REF2021"5)-and hence of the institutional funding that depends on this-concerns evidence of research impact.

Evaluating translations might involve multiple, conflicting sets of criteria. A first metric might be the reach of a give theory or framework: how many of UX practitioners are aware of the subject of the translation work, and to what extent do they know its contents? Although this might be measured through a survey, this would only show formal knowledge of a list of concepts, and may be decorrelated from knowing the framework or theory in a way that is relevant to design activities. A second step would be to assess whether relevant concepts are being used in design projects. Such questions might be framed in terms of breadth (how many projects?) or depth (how much of the framework / theory is used in a project?). This could also be phrased in terms of process (is the framework / theory supporting design decisions?) or outcomes (do the designed artefacts or ultimate particulars reflect the framework / theory?). Discussions of the nature of design as a rigorous discipline whose process should be accountable $[56,61]$ offer us tools to assess the rigor of the process, but not necessarily whether and how theory has actually come into use. In our case, the trajectories framework itself might be used to assess use, as it provides, in its own words, an "analytical lens", but this would only tell us whether an artefact has features that correspond to trajectories, not whether it has been designed with the framework. Thus, it remains a challenge for $\mathrm{HCl}$ to develop ways to fully capture the deeper impact of $\mathrm{HCl}$ research on non-academic organizations. We hope that publishing case studies such as this is a step towards this.

Finally, the work we've described above shows that a $\mathrm{HCl}$ conceptual framework can impact organizations and production processes in ways that are subtler than direct influence on specific design projects. For example, several stakeholders considered trajectories to be an "internal propaganda tool" that they could leverage to gain the collaboration of other product teams.

\subsection{Limitations and prior conceptualizations of research-practice relations}

We note a limitation in that our study focusses primarily on frameworks and theory that have been generated within $\mathrm{HCl}$ research communities. In this way, our paper does not consider the possibility of theoretical concepts from the work of UX practitioners themselves influencing $\mathrm{HCl}$ research in return. The possibility is certainly important, perhaps most critically in $\mathrm{HCl}$ 's own conceptualisations of UX itself.

5 https://www.ref.ac.uk 
Finally, to some extent, the kinds of engagement between research and practice that we document here may predate the work we described even if they have not been articulated in $\mathrm{HCl}$ in quite the way we have presented here. Our research consolidates and builds upon discussions in $\mathrm{HCl}$ that have been ongoing for some time. For example, in the late 1980s, Long and Dowell debated various ways of thinking about $\mathrm{HCl}$ as a discipline, describing how its practice elements (amongst other things including knowledge, and problem focus) could relate to craft, scientific or engineering conceptualizations of $\mathrm{HCl}$ [34]. But perhaps the most critical recent work in this area is Gray et al.'s discussion of "trickle-down" and "bubble-up" conceptualizations of research-practice relations [27], which describes both researcher-led and practitioner-led elements and presents an "ideal cycle-around between the research and practice communities" (Figure 11). While Gray et al.'s work was based upon an interview study with practitioners, our study involved sustained immersion in the UX practices of MediaOrg, which enables us to build upon and refine the model in a number of ways. For starters, we have enriched concepts of researcher- or practitioner-led modes. Primarily, however, we introduce a third mode-co-production-which is not discussed by Gray et al. Finally, our account of the various interventions goes some way to articulating Gray et al.'s recommendation to further study "how designers select methods, opportunistically apply them to a specific design situation, and adapt or refine methods over time to suit the needs of specific design contexts" $[27$, p. 731$]$ so as to better understand actual practitioners' use of methods in situ.

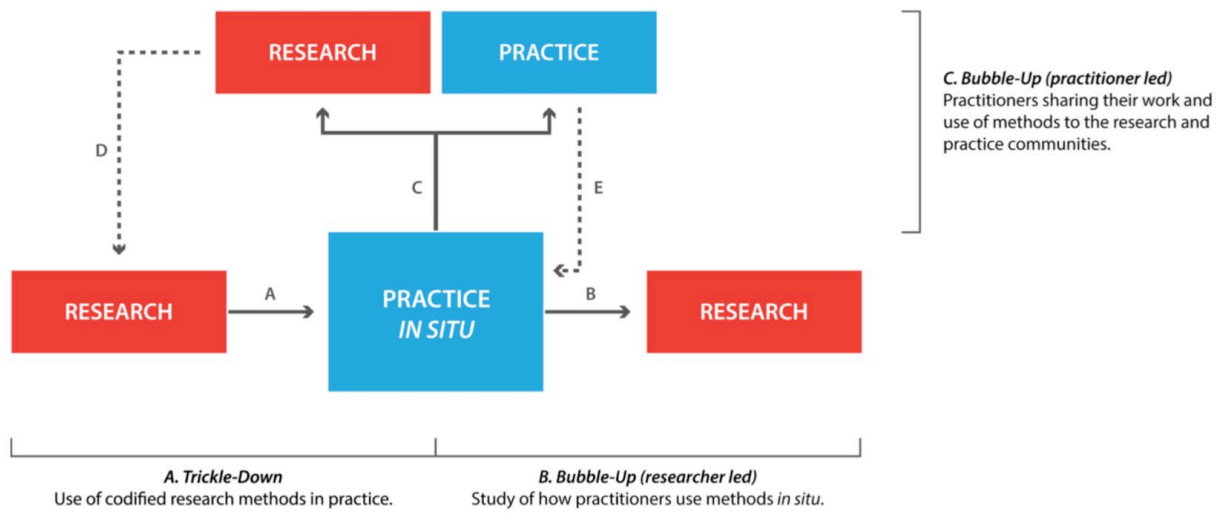

Figure 11 Gray et al.'s idealized model of research-practice relations (figure reproduced from [27])

\section{CONCLUSIONS}

To draw to a conclusion, bridging the gap between academic $\mathrm{HCl}$ research and the work of industry UX practitioners is indeed a major challenge. Our intention in writing this paper has been to contribute to our understanding of the nature of the challenge and how it might be addressed. First, by reviewing the existing literature, we have clarified the nature of the gap, identifying two key dimensions-between academic $\mathrm{HCl}$ research and the work of UX practitioners on the one hand and between general theory and particular artefacts on the other. Second, by reflecting on our experience of engaging with a major company to try and translate a specific $\mathrm{HCl}$ theory for-and with-UX practitioners, we have been able to document 
various kinds of translational resource that might help bridge this gap. Moreover, we have identified three different modes for creating such resources researcher-driven, co-created boundary objects, and UX practitioner-driven. Of course, many challenges remain for further research. We need to see whether these findings generalize beyond this specific case study. MediaOrg is notable for being a large organisation with a dedicated and active R\&D division that routinely collaborates with Universities, which was undoubtedly a factor in initially gaining traction with the trajectories theory, being able to host researchers, and also facilitating connections with the UX division. Few organisations, even large companies let along small UX companies, have such a significant R\&D capability so that it may be necessary to consider what alternative structures might fulfil this role, for example University, local or nationally-funded networks and impact schemes. We should consider the thorny question of how such translations might be evaluated, and indeed how the "impact" of academic research might be evaluated. Finally, we should look for examples of and possibilities for the work of UX practitioners being translated into $\mathrm{HCl}$ research, something that calls for a deeper engagement between our complex set of communities.

We note with some irony that while our paper has focussed on unpacking relations between $\mathrm{UX}$ practitioners and $\mathrm{HCl}$ academics and the ways in which translations between these complex communities may be conducted, our reporting of this work has primarily been targeted at the academic $\mathrm{HCl}$ community alone (specifically, publishing this work, framed as addressing theory, in an academic journal). Although our intention has been to communicate to academic research to begin with, we note that future work needs to share this very research with practitioners themselves, within practitioners' own fora (conferences, etc.). This activity itself involves further translations-most probably of Mode 1 form-where we map out the different types of engagements between research and practice but for a non-academic audience. Practitioners interested in embarking on closer relations to $\mathrm{HCl}$ research could benefit from awareness of the schema we have presented, while at the same time we as investigators can benefit from further feedback and evaluation of the validity of our framework in how it goes about mapping out the 'gaps'.

\section{ACKNOWLEDGMENTS}

This work has been supported by the Engineering and Physical Sciences Research Council through the following grants: "From Human Data to Personal Experience" [grant number EP/M02315X/1]; "Dream Fellowship: Inspiration, Immersion and Impact with the Creative Industrie" [grant number EP/J005215/1]; and "From theory to practice: putting $\mathrm{HCl}$ frameworks to work" [grant number EP/K025848/1].

\section{REFERENCES}

1 Jordan Beck and Hamid R. Ekbia. 2018. The Theory-Practice Gap as Generative Metaphor. In Proceedings of the 2018 CHI Conference on Human Factors in Computing Systems (CHI '18). ACM, New York, NY, USA, Paper 620, 11 pages. https://doi.org/10.1145/3173574.3174194

2 Steve Benford and Gabriella Giannachi. 2008. Temporal Trajectories in Shared Interactive Narratives. In Proceedings of the SIGCHI Conference on Human Factors in Computing Systems (CHI '08), 73-82. https://doi.org/10.1145/1357054.1357067 
3 Steve Benford and Gabriella Giannachi. 2011. Performing Mixed Reality. MIT Press, Cambridge, Mass.

4 Steve Benford, Gabriella Giannachi, Boriana Koleva, and Tom Rodden. 2009. From interaction to trajectories: designing coherent journeys through user experiences. In Proceedings of the SIGCHI Conference on Human Factors in Computing Systems (CHI '09), 709-718. https://doi.org/10.1145/1518701.1518812

5 Elizabeth Buie, Susan Dray, Keith Instone, Jhilmil Jain, Gitte Lindgaard, and Arnie Lund. 2010. How to Bring $\mathrm{HCl}$ Research and Practice Closer Together. In CHI '10 Extended Abstracts on Human Factors in Computing Systems (CHI EA '10), 3181-3184. https://doi.org/10.1145/1753846.1753951

6 Elizabeth Buie, Clare J. Hooper, and Aaron Houssian. 2013. Research-practice Interaction: Building Bridges, Closing the Gap. In CHI '13 Extended Abstracts on Human Factors in Computing Systems (CHI EA'13), 2493-2496. https://doi.org/10.1145/2468356.2468813

7 Michel Callon. 1984. Some elements of a sociology of translation: domestication of the scallops and the fishermen of St Brieuc Bay. The Sociological Review 32: 196-233. https://doi.org/10.1111/j.1467954X.1984.tb00113.x

8 John M. Carroll and Mary Beth Rosson. 2007. Participatory design in community informatics. Design Studies 28, 3: 243-261. https://doi.org/10.1016/j.destud.2007.02.007

9 Ko-Le Chen, Rachel Clarke, Teresa Almeida, Matthew Wood, and David S. Kirk. 2017. Situated Dissemination Through an HCI Workplace. In Proceedings of the 2017 CHI Conference on Human Factors in Computing Systems (CHI '17), 2078-2090. https://doi.org/10.1145/3025453.3025696

10 Gilbert Cockton and Alan Woolrych. 2002. Sale Must End: Should Discount Methods Be Cleared off HCl's Shelves? interactions 9, 5: 13-18. https://doi.org/10.1145/566981.566990

11 Lucas Colusso, Cynthia L. Bennett, Gary Hsieh, and Sean A. Munson. 2017. Translational Resources: Reducing the Gap Between Academic Research and HCI Practice. In Proceedings of the 2017 Conference on Designing Interactive Systems (DIS '17), 957-968. https://doi.org/10.1145/3064663.3064667

12 Lucas Colusso, Ridley Jones, Sean A. Munson, and Gary Hsieh. 2019. A Translational Science Model for $\mathrm{HCl}$. In Proceedings of the $2019 \mathrm{CHI}$ Conference on Human Factors in Computing Systems (CHI '19). ACM, New York, NY, USA, Paper 1, 13 pages. https://doi.org/10.1145/3290605.3300231

13 Geoff Cooper and John Bowers. 1995. Representing the user: Notes on the disciplinary rhetoric of human-computer interaction. In The Social and Interactional Dimensions of Human-Computer Interfaces, Peter J. Thomas (ed.). Cambridge University Press, Cambridge, 48-66.

14 Dimitrios Darzentas, Raphael Velt, Richard Wetzel, Peter J. Craigon, Hanne G. Wagner, Lachlan D. Urquhart, and Steve Benford. 2019. Card Mapper: Enabling Data-Driven Reflections on Ideation Cards. In Proceedings of the $2019 \mathrm{CHI}$ Conference on Human Factors in Computing Systems (CHI '19). ACM, New York, NY, USA, Paper 571, 15 pages. https://doi.org/10.1145/3290605.3300801.

15 Brian C. Drolet, Nancy M. Lorenzi. 2011. Translational research: understanding the continuum from bench to bedside. Translational Research, Volume 157, Issue 1, 2011, Pages 1-5, ISSN 1931-5244. https://doi.org/10.1016/j.trsl.2010.10.002.

16 Paul Dourish. 2006. Implications for Design. In Proceedings of the SIGCHI Conference on Human Factors in Computing Systems (CHI '06), 541-550. https://doi.org/10.1145/1124772.1124855 
17 Engineering and Physical Sciences Research Council. 2012. Human Computer Interaction Theme Day and Survey Report, March 2012. https://epsrc.ukri.org/newsevents/pubs/report-of-the-epsrc-humancomputer-interaction-theme-day-and-survey/ (verified May 2019)

18 Per Ehn. 1988. Work-Oriented Design of Computer Artifacts. University of Umeå, Umeå, Sweden.

19 Daniel Fallman. 2008. The Interaction Design Research Triangle of Design Practice, Design Exploration, and Design Studies. Design Issues, 24, 3, 4-18. https://doi.org/10.1162/desi.2008.24.3.4

20 Daniel Fallman and Erik Stolterman. 2010. Establishing criteria of rigour and relevance in interaction design research. Digital Creativity 21, 4: 265-272. https://doi.org/10.1080/14626268.2010.548869

21 Haakon Faste. 2017. Intuition in Design: Reflections on the Iterative Aesthetics of Form. In Proceedings of the 2017 CHI Conference on Human Factors in Computing Systems (CHI '17), 3403-3413. https://doi.org/10.1145/3025453.3025534

22 Peter Galison. 1999. Trading Zone: Coordinating Action and Belief. In Biagioli, Mario (Ed.) The Science Studies Reader, pp. 137-160. NY: Routledge.

23 Jesse James Garrett. 2002. The elements of user experience: User-centered design for the Web. New Riders, Indianapolis.

24 William Gaver. 2012. What Should We Expect from Research Through Design? In Proceedings of the SIGCHI Conference on Human Factors in Computing Systems (CHI '12), 937-946. https://doi.org/10.1145/2207676.2208538

25 Sabine Geldof and Joannes Vandermeulen. 2008. A Practitioner's View of Human-Computer Interaction Research and Practice. Artifact 1, 3: 134-141. https://doi.org/10.1080/17493460701800181

26 Elizabeth Goodman, Erik Stolterman, and Ron Wakkary. 2011. Understanding interaction design practices. In Proceedings of the SIGCHI Conference on Human Factors in Computing Systems, 1061-1070. https://doi.org/10.1145/1978942.1979100

27 Colin M. Gray, Erik Stolterman, and Martin A. Siegel. 2014. Reprioritizing the Relationship Between $\mathrm{HCl}$ Research and Practice: Bubble-up and Trickle-down Effects. In Proceedings of the 2014 Conference on Designing Interactive Systems (DIS '14), 725-734. https://doi.org/10.1145/2598510.2598595

28 Kristina Höök and Jonas Löwgren. 2012. Strong concepts: Intermediate-level knowledge in interaction design research. ACM Transactions on Computer-Human Interaction 19, 3: 1-18. https://doi.org/10.1145/2362364.2362371

29 Eva Hornecker. 2010. Creative Idea Exploration Within the Structure of a Guiding Framework: The Card Brainstorming Game. In Proceedings of the Fourth International Conference on Tangible, Embedded, and Embodied Interaction (TEI '10), 101-108. https://doi.org/10.1145/1709886.1709905

30 Lucy Kimbell. 2011. Rethinking Design Thinking: Part I. Design and Culture 3, 3: $285-306$. https://doi.org/10.2752/175470811X13071166525216

31 Dirk Knemeyer and Eric Svoboda. User Experience - UX. The Glossary of Human Computer Interaction. Retrieved August 23, 2017 from https://www.interaction-design.org/literature/book/the-glossary-ofhuman-computer-interaction/user-experience-ux

32 Bruno Latour and Steve Woolgar. 1979. Laboratory life: the social construction of scientific facts. Sage Publications, Beverly Hills. 
33 Jean Lave and Etienne Wenger. 1991. Situated learning: legitimate peripheral participation. Cambridge University Press, Cambridge.

34 John Long and John Dowell. 1990. Conceptions of the discipline of $\mathrm{HCl}$ : craft, applied science, and engineering. In Proceedings of the fifth conference of the British Computer Society, Human-Computer Interaction Specialist Group on People and computers V, Alistair Sutcliffe and Linda Macaulay (Eds.). Cambridge University Press, New York, NY, USA, 9-32.

35 Jonas Löwgren. 2013. Annotated Portfolios and Other Forms of Intermediate-level Knowledge. interactions 20, 1: 30-34. https://doi.org/10.1145/2405716.2405725

36 Chris Mears. 2013. User Journeys - The Beginner's Guide. The UX Review. Retrieved September 14, 2017 from http://theuxreview.co.uk/user-journeys-beginners-guide/

37 Florian Mueller, Martin R. Gibbs, Frank Vetere, and Darren Edge. 2014. Supporting the Creative Game Design Process with Exertion Cards. In Proceedings of the 32Nd Annual ACM Conference on Human Factors in Computing Systems (CHI '14), 2211-2220. https://doi.org/10.1145/2556288.2557272

38 Harold G. Nelson and Erik Stolterman. 2003. Design Judgement: Decision-Making in the "Real" World. The Design Journal 6, 1: 23-31. https://doi.org/10.2752/146069203790219344

39 Harold G. Nelson and Erik Stolterman. 2012. The Design Way: Intentional Change in an Unpredictable World. The MIT Press, Cambridge, Mass.

40 Donald A. Norman. 2010. The Research-practice Gap: The Need for Translational Developers. interactions 17, 4: 9-12. https://doi.org/10.1145/1806491.1806494

41 Antti Oulasvirta and Kasper Hornbæk. 2016. HCI Research as Problem-Solving. In Proceedings of the 2016 CHI Conference on Human Factors in Computing Systems (CHI '16). ACM, New York, NY, USA, 4956-4967. https://doi.org/10.1145/2858036.2858283

42 John Pruitt and Tamara Adlin. 2006. The persona lifecycle: keeping people in mind throughout product design. Elsevier: Morgan Kaufmann Publishers, an imprint of Elsevier, Amsterdam; Boston.

43 Dan Ramsden. 2016. Trajectories for UX designers. This Is DanRamsden.com. Retrieved July 20, 2017 from http://danramsden.com/wp-content/uploads/2016/05/Trajectories_danRamsden.pdf

44 Andreas Reckwitz. 2002. Toward a Theory of Social Practices: A Development in Culturalist Theorizing. European Journal of Social Theory 5, 2: 243-263. https://doi.org/10.1177/13684310222225432

45 Stuart Reeves. 2019. How UX Practitioners Produce Findings in Usability Testing. ACM Trans. Comput.Hum. Interact. 26, 1, Article 3 (January 2019), 38 pages. https://doi.org/10.1145/3299096

46 Stuart Reeves, Sara Ljungblad, Elizabeth Buie, Torkil Clemmensen, Susan Dray, Rowanne Fleck, Colin M. Gray, Keith Instone, Carine Lallemand, Gitte Lindgaard, Andrea Resmini, Marty Siegel, Simone Stumpf, Raphael Velt, and Selena Whitehead. 2018. Proceedings of the Nottingham Symposium on Connecting $\mathrm{HCl}$ and $\mathrm{UX}$. Technical report, University of Nottingham, 2018. http://dx.doi.org/10.17639/8vez-c741

47 Andrea Resmini and Luca Rosati. 2009. Information Architecture for Ubiquitous Ecologies. In Proceedings of the International Conference on Management of Emergent Digital EcoSystems (MEDES '09), 29:196-199. https://doi.org/10.1145/1643823.1643859 
48 Yvonne Rogers. 2004. New theoretical approaches for human-computer interaction. Annual Review of Information Science and Technology 38, 1: 87-143. https://doi.org/10.1002/aris.1440380103

49 Yvonne Rogers. 2012. HCI Theory: Classical, Modern, and Contemporary. Synthesis Lectures on HumanCentered Informatics 5, 2: 1-129. https://doi.org/10.2200/S00418ED1V01Y201205HCI014

50 Dan Saffer. 2010. Designing for interaction: creating innovative applications and devices. New Riders, Berkeley, CA.

51 Corina Sas, Steve Whittaker, Steven Dow, Jodi Forlizzi, and John Zimmerman. 2014. Generating implications for design through design research. 1971-1980. https://doi.org/10.1145/2556288.2557357

52 Theodore R. Schatzki, K. Knorr-Cetina, and Eike von Savigny (eds.). 2001. The practice turn in contemporary theory. Routledge, New York.

53 Ben Shneiderman, mc Schraefel, Elizabeth Churchill, Matt Jones, Jonathan Lazar, Gary Olson, Judith Olson, Catherine Plaisant, jennifer Preece, and Terry Winograd. 2017. How the CHI Community Got Its Groove: And Changed the World! In Proceedings of the 2016 CHI Conference Extended Abstracts on Human Factors in Computing Systems (CHI EA '17), 2-2. https://doi.org/10.1145/3027063.3056454

54 Susan Leigh Star. 2010. This is Not a Boundary Object: Reflections on the Origin of a Concept. Science, Technology \& Human Values 35, 5: 601-617. https://doi.org/10.1177/0162243910377624

55 Susan Leigh Star and James R. Griesemer. 1989. Institutional Ecology, "Translations" and Boundary Objects: Amateurs and Professionals in Berkeley's Museum of Vertebrate Zoology, 1907-39. Social Studies of Science 19, 3: 387-420.

56 Erik Stolterman. 2008. The Nature of Design Practice and Implications for Interaction Design Research. International Journal of Design 2, 1: 55-65.

57 Stephen L. Vargo and Robert F. Lusch. 2004. Evolving to a New Dominant Logic for Marketing. Journal of Marketing 68, 1 (January 2004), 1-17. https://doi.org/10.1509/jmkg.68.1.1.24036

58 Raphael Velt. 2018. Putting trajectories to work: translating a $\mathrm{HCl}$ framework into design practice. Unpublished PhD thesis, University of Nottingham.

59 Raphael Velt, Steve Benford, and Stuart Reeves. 2017. A Survey of the Trajectories Conceptual Framework: Investigating Theory Use in $\mathrm{HCl}$. In Proceedings of the $2017 \mathrm{CHI}$ Conference on Human Factors in Computing Systems (CHI '17), 2091-2105. https://doi.org/10.1145/3025453.3026022

60 Annika Waern and Jon Back. 2017. Activity As the Ultimate Particular of Interaction Design. In Proceedings of the 2017 CHI Conference on Human Factors in Computing Systems (CHI '17), 3390-3402. https://doi.org/10.1145/3025453.3025990

61 Tracee Vetting Wolf, Jennifer A. Rode, Jeremy Sussman, and Wendy A. Kellogg. 2006. Dispelling "Design" As the Black Art of CHI. In Proceedings of the SIGCHI Conference on Human Factors in Computing Systems (CHI '06), 521-530. https://doi.org/10.1145/1124772.1124853

62 Indi Young. 2008. Mental Models: Aligning Design Strategy with Human Behavior. Rosenfeld Media.

63 John Zimmerman, Jodi Forlizzi, and Shelley Evenson. 2007. Research Through Design As a Method for Interaction Design Research in $\mathrm{HCl}$. In Proceedings of the SIGCHI Conference on Human Factors in Computing Systems (CHI '07), 493-502. https://doi.org/10.1145/1240624.1240704 
Received XXX; revised XXX; accepted XXX 